University of Nebraska - Lincoln

DigitalCommons@University of Nebraska - Lincoln

Faculty Publications, Department of Psychology

Psychology, Department of

December 2003

\title{
Barriers to Community Mental Health Services for Latinos: Treatment Considerations
}

Haig Kouyoumdjian

University of Nebraska-Lincoln

Byron L. Zamboanga

Smith College, bzamboan@smith.edu

David J. Hansen

Univertsity of Nebraska-Lincoln, dhansen1@unl.edu

Follow this and additional works at: https://digitalcommons.unl.edu/psychfacpub

Part of the Psychiatry and Psychology Commons

Kouyoumdjian, Haig; Zamboanga, Byron L.; and Hansen, David J., "Barriers to Community Mental Health Services for Latinos: Treatment Considerations" (2003). Faculty Publications, Department of Psychology. 128.

https://digitalcommons.unl.edu/psychfacpub/128

This Article is brought to you for free and open access by the Psychology, Department of at DigitalCommons@University of Nebraska - Lincoln. It has been accepted for inclusion in Faculty Publications, Department of Psychology by an authorized administrator of DigitalCommons@University of Nebraska - Lincoln. 
This is an electronic version of an article published in Clinical Psychology: Science and Practice 10:4 (Winter 2003), pp. $394-422$. Copyright (C) 2003 Oxford University Press. Clinical Psychology: Science and Practice is currently published by Blackwood Publishing; http://www.blackwellpublishing.com/journal.asp?ref=0969-5893\&site=1. Used by permission.

\title{
Barriers to Community Mental Health Services for Latinos:Treatment Considerations
}

\author{
Haig Kouyoumdjian, Byron L. Zamboanga, and David J. Hansen \\ University of Nebraska-Lincoln
}

\begin{abstract}
The underutilization of mental health services by Latinos has been a growing concern in research and clinical practice. This has become increasingly important as the population of Latinos in the United States rapidly rises and the evidence that many are not receiving needed mental health services accumulates. To provide an understanding of the issues, this article provides an overview of risk factors that may influence the mental health of Latinos and examines prevalence rates of psychopathology and service utilization trends. This article then presents a comprehensive review of the socioeconomic, cultural, and psychotherapeutic barriers that prevent Latinos from receiving community mental health services. Treatment recommendations to increase the access and utilization of community mental health services by Latinos are discussed.
\end{abstract}

Key words: Latinos, barriers, mental health service, treatment, culture

The underutilization of mental health services by Latino families has been a growing concern in research and clinical practice. Various socioeconomic and cultural factors place Latinos at risk for developing mental health problems, and research suggests that many Latinos may be in need of receiving mental health services (e.g., Canabal \& Quiles, 1995; Padilla, Ruiz,

Address correspondence to Haig Kouyoumdjian, Department of Psychology, University of Nebraska-Lincoln, Lincoln, NE 68588-0308.

Byron L. Zamboanga is now at the Department of Psychology, Smith College, Northhampton, MA 01063.
\& Alvarez, 1975; Rogler, Cortes, \& Malgady, 1991). Substantial research also indicates that Latinos underutilize mental health services (e.g., Alvidrez, 1999; Bui \& Takeuchi, 1992; Flaskerud \& Hu, 1992; Sue, 1977; Sue, Fujino, Hu, Takeuchi, \& Zane, 1991; Vega, Kolody, Aguilar-Gaxiola, \& Catalano, 1999; Wells, Klap, Koike, \& Sherbourne, 2001). The notable discrepancy between Latinos' needs for services and their underutilization highlights the need to better understand and address the mental health concerns of Latino families.

Stronger efforts to ensure that Latino families receive the mental health care they need are becoming increasingly important as the population of Latinos in the United States rapidly increases. Between 1990 and 2000, the Latino population increased by $57.9 \%$, while the increase in the total U.S. population was only $13.2 \%$ (U.S. Census Bureau, 2001a). In 1996, Latinos comprised about $10 \%$ of the U.S. population and $39 \%$ of the U.S. ethnic minority population, making them the second largest minority group in the United States (U.S. Census Bureau, 1996). By the year 2000, Latinos comprised $12.5 \%$ of the U.S. population (U.S. Census Bureau, 2001a). It is estimated that by 2020, Latinos will become the largest ethnic minority group in the United States, comprising about $15 \%$ of the U.S. population (U.S. Census Bureau, 1993). Recent estimates predict that by 2050, Latinos will comprise about $25 \%$ of the. U.S. population and slightly more than $50 \%$ of the ethnic minority population (U.S. Census Bureau, 2001a). Improving the mental health care of Latinos is necessary to 
help ensure that Latinos receive the mental health services they need.

As the population of Latinos in the United States rapidly grows, the heterogeneity of Latinos is likely to increase in a number of ways including place of origin, cultural values, socioeconomic status, and English-language competency. Although Latinos may share some common characteristics, there can be significant within- and between-group variability. Consequently, one of the challenges in discussing mental health issues for Latinos involves the vast cultural heterogeneity of this population. Considering each subgroup of Latinos (e.g., refugees, those with varying socioeconomic status, geographical origins, or levels of acculturation) in the review of barriers to community mental health services and recommendations for treatment delivery is not within the scope of this paper; however, in an effort to remain sensitive to both the within- and between-group variability among Latinos, the authors exercise caution throughout the paper to avoid making over-generalizations.

This article begins with an overview of the mental health status of Latinos in the United States, providing a general background to the article. This highlights the need to consider thoroughly the various barriers to community mental health services many Latinos experience and to make thoughtful recommendations to improve the access of these services by Latinos. There have been several reviews that have specifically focused on the use of mental health services by Latinos (e.g., Acosta, 1979; Greenblatt \& Norman, 1982; Keefe, 1979; Keefe \& Casas, 1980; Woodward, Dwinell, \& Arons, 1992). This article is unique by carrying out two main objectives. First, it provides a current and thorough examination of socioeconomic, cultural, and psycho-therapeutic barriers that prevent Latinos from receiving the mental health services they need. Second, this article presents comprehensive clinical recommendations based on existing barriers to help increase the utilization of community mental health services by Latinos.

\section{PREVALENCE RATES OF PSYCHO- PATHOLOGY AMONG U.S. LATINOS}

Some empirical literature has revealed ethnic differences in psychopathology. Much of the research with Latinos has focused on Mexican Americans. In studies comparing the prevalence of psychiatric disorders in whites, African Americans, and Latinos, higher rates of depression, depressive symptoms, and diagnosed mental illness were found in Latinos (Radloff, 1977; Vernon \& Roberts, 1982). Epidemiological studies conducted in the Los Angeles area revealed high prevalence rates of alcohol abuse and dependency in Mexican American men. Results further showed high rates of phobias in Mexican American women over the age of 40 (Karno et al., 1987). Although many studies suggest that Latinos are more likely to experience higher rates of psychopathology than Whites, some empirical evidence suggests otherwise. For instance, a study conducted in a Los Angeles county mental health facility found fewer Latinos diagnosed with major affective and psychotic disorders than Whites (Flaskerud \& Hu, 1992). Other studies have shown Mexican Americans reporting fewer symptoms of psychophysiological distress than Whites, even after controlling for the effects of socioeconomic status (Antunes, Gordon, Gaitz, \& Scott, 1974; Gaitz \& Scott, 1974). Although differences in the psychopathology of Latinos and Whites may exist, the direction of these differences remains inconsistent and likely there are greater within-group than between-group differences.

Contrary to many reports surrounding ethnic differences in the mental health status between Latinos and Whites, some evidence suggests similarities between these groups. For example, the Epidemiological Catchment Area (ECA) program examined the prevalence of major psychiatric disorders in the United States during the 1980s. Results from the ECA revealed no differences in the lifetime prevalence and active case rates of psychiatric disorders between Latinos (33\% and 20\%, respectively) and Whites (32\% and 19\%, respectively; Regier \& Kaelber, 1995). Another study found Mexican Americans and Whites to have the same frequency of mental retardation, psychosis, neurosis, psychophysiological problems, personality disorder, and behavior disorder (Sue, 1977). Furthermore, no differences were revealed between Mexican Americans and non-Hispanic Whites in the diagnosis of major depression or in mood symptoms related to major depression (Golding \& Lipton, 1990).

In summary, research comparing the psychopathology prevalence rates between Latinos and other ethnic groups has yielded mixed findings. There are several possible explanations for these reports. First, because Latinos are an ethnoculturally heterogeneous 
group, one would anticipate greater within-group differences than between-group differences in psychopathology rates. Consistent with this suggestion, one study showed Mexican Americans reporting significantly higher scores of depression than other Latino subgroups (e.g., Puerto Rican, Cuban, other; Roberts \& Sobhan, 1992). The ethnocultural variability of Latino samples may, to some extent, contribute to these mixed findings. Hence, it is likely that the samples in various research studies consisted of different Latino subgroups. Flaskerud and $\mathrm{Hu}$ (1992) suggest that problems with methodology, including sampling bias, diagnoses based solely on questionnaires, and the use of untrained interviewers, may contribute to the inconsistency in the literature. They also suggest that the use of mainstream instruments to measure psychopathology may have validity problems when used with Latinos. Finally, they assert that many studies do not control for confounding variables, including sex, age, and socioeconomic status. In addition to explanations for the variability of psychopathology prevalence rates among ethnocultural groups provided by Flaskerud and $\mathrm{Hu}$, differences in acculturation levels and acculturative stress factors may account for some inconsistencies. Therefore, to better understand the psychopathology of Latinos, it is important to examine the influence of socioeconomic and cultural variables on the mental health status of Latinos.

\section{OVERVIEW OF RISK FACTORS THAT MAY INFLUENCE THE MENTAL HEALTH STATUS OF LATINOS}

There are a number of potential risk factors linked to the mental health status of Latinos. These risk factors include socioeconomic background, acculturation, and acculturative stress.

\section{Socioeconomic Factors}

A review of the literature shows an association between low socioeconomic status and higher rates of depression, more hostility, and greater exposure to stress (Adler et al., 1994). It has been well documented that the number of individuals experiencing psychological maladjustment and mental health problems is highest among the most socioeconomically disadvantaged members of society (e.g., Dohrenwend et al., 1980; Lang, Munoz, Bernal, \& Sorenson, 1982).
Given these findings, it reasonably follows that ethnoculturally diverse individuals who come from low socioeconomic conditions may be more vulnerable to chronic stress than individuals from middle and upper socioeconomic backgrounds (Aponte \& Barnes, 1995). In fact, much of the research on the relationship between socioeconomic status and mental health in Latinos reveals poor socioeconomic conditions to be linked to depression (e.g., Canabal \& Quiles, 1995; Cuellar \& Roberts, 1997). Hence, socioeconomic risk factors are of particular concern for Latinos because many of them migrate to environments that are economically and psychologically challenging (Belitz \& Valdez, 1997).

\section{Acculturation}

Acculturation refers to the psychosocial changes an individual or group experiences when interacting with another culture (Alvidrez, Azocar, \& Miranda, 1996). Furthermore, acculturation is a bidirectional interactive process between an individual and the host culture (Berry, 1993). The degree of an individual's acculturation depends on changes in attitudes, behaviors, cognitions, identity, and values as a result of contact with the host culture (Berry, 1990; Ponce \& Atkinson, 1989). Therefore, the more acculturated individual will retain less of his or her native culture (e.g., values, beliefs, traditions) and experience more changes in thinking and behavior as a result of contact with the host culture.

Compared to other U.S. ethnic groups, the role of acculturation is particularly important in Latinos because they maintain closer ties to their native country by preserving their language and cultural characteristics (Acosta, 1979; Sandoval \& De La Roza, 1986). Because most Latinos tend to maintain a strong cultural identity, it can be a challenging process for them to integrate the cultural characteristics of the majority group with their traditional cultural beliefs and values. In fact, being a Latino immigrant can be a significant stressor that may place these individuals at risk for developing mental health problems (Cervantes, Salgado de Snyder, \& Padilla, 1989; Rogler, Gurak, \& Cooney, 1987). Stressors that Latino immigrants are likely to experience include self-pressures to succeed in the new country, difficulties in communication, and leaving behind family and friends (Salgado de Sny- 
der, 1987). However, to date, the findings on the mental health of immigrant Latinos have been mixed.

The relationship between acculturation and mental health status is an intricate and complex issue (Griffith, 1983). Numerous studies have shown a relationship between low levels of acculturation and problems in adjustment and mental health (e.g., Lang et al., 1982; Neff, 1986; Salgado de Snyder, 1987). The link between low acculturation levels and mental health problems may be explained in part by recent immigrants leaving their own support system and entering a new society with minimal or no English-language proficiency skills, making it more difficult to establish a new social network (Rogler et al., 1991). As a result, these individuals may experience an increase in their psychological distress. On the other hand, highly acculturated individuals may experience psychological stressors such as the challenge of adjusting to the cultural values of the host society (Dressler \& Bernal, 1982). Consistent with this suggestion, high levels of acculturation in Latinos have been linked to several psychological maladjustment behaviors including greater levels of depressive symptoms (Neff \& Hoppe, 1993), more psychopathological symptoms (Miranda \& White, 1993), higher lifetime rates of phobia (Burnam, Hough, Karno, Escobar, \& Telles, 1987), and higher chemical dependency rates (Burnam et al., 1987).

Other research suggests that retaining traditional support networks and simultaneously adopting cultural aspects of the dominant society facilitates positive mental health outcomes (Ramirez, 1983; Szapocznik \& Kurtines, 1980a, 1980b). Consistent with this suggestion, research shows that bicultural Latinos tend to report fewer depressive symptoms than high or low acculturated Latinos (Miranda \& Umhoefer, 1998). Similarly, others found that the most well adjusted Latinos in a community sample were bicultural, but that these Latinos leaned slightly toward their Latino culture while engaging in behaviors characteristic of the majority group (Lang et al., 1982). Although bicultural status appears to be adaptive for Latinos' mental health, achieving and maintaining this balance can be a challenging task and is likely to be influenced by a host of individual (e.g., identity formation), family, and contextual factors (e.g., monocultural vs. multicultural communities).

In summary, research has revealed inconsistent findings in the relationship between acculturation lev- el and mental health status. Despite the empirical literature on the association between acculturation and mental health, there does not appear to be any clear conclusive evidence regarding the specific direction of the relationship between acculturation and mental health status in Latinos.

\section{Acculturative Stress}

Because the findings on the relationship between acculturation and psychopathology in Latinos are inconsistent and some aspects of acculturation are likely to be associated with mental health, an important risk factor to consider is acculturative stress. Acculturation refers to the changes individuals go through when they begin to live in a new culture, and acculturative stress refers to the stress that arises from the process of acculturation (Williams \& Berry, 1991). Some studies suggest that high levels of acculturative stress may place individuals at risk for the development of psychological problems (Hovey \& King, 1996; Salgado de Snyder, 1987; Williams \& Berry, 1991). In fact, these studies show that acculturative stress can yield a variety of health-risk behaviors and emotions including depression, anxiety, psychosomatic symptoms, suicidal ideation, and identity confusion. Moreover, acculturative stress has been reported to influence Latinos' occupational functioning, decisionmaking abilities, and physical health through-out their lives (Smart \& Smart, 1991).

There are several risk factors that may intensify the acculturative stress experienced by Latinos. Risk factors include, but are not limited to, a lack of social support in the new community (e.g., a lack of immediate- and extended-family support), low socioeconomic status (e.g., low education, low income, unemployment), and cognitive attributes (e.g., poor expectations and attitudes toward acculturation) (Berry \& Kim, 1988; Williams \& Berry, 1991). Lack of English-language competency can also contribute to increased acculturative stress (Padilla, 1980). Final$1 y$, acculturative stress can originate from the general lack of successful role models for Latinos (Smart \& Smart, 1991). The result may be a loss of goal orientation and having to accept remaining in a lower socioeconomic status. Unfortunately, many migrating Latinos experience a number of these characteristics, which places them at risk for experiencing acculturative stress. For instance, migrating Latinos of- 
ten have little social support (Rogler et al., 1991) and come from low socioeconomic backgrounds (Catanzarite, 2000). In addition, some may experience language barriers, have limited exposure to successful Latino role models, and undergo feelings of alienation (Dressler \& Bernal, 1982).

\section{MENTAL HEALTH SERVICE UTILIZATION TRENDS AMONG LATINOS}

The within-group variability of Latinos (e.g., socioeconomic factors, acculturation levels, acculturative stress factors) may be associated with unique life experiences and could therefore influence the mental health service utilization rates among Latino subgroups. Unfortunately however, no research to date has compared the service utilization patterns among specific Latino subgroups. Instead, many investigations have focused on the service utilization patterns of the general Latino community. Although studies in this area remain limited, the existing body of literature thus far has shed valuable insight on the service utilization trends and patterns of Latinos.

\section{Low Utilization Rates}

Relatively few ethnically diverse individuals experiencing mental health problems seek the services of mental health personnel (e.g., psychiatrists, psychologists, social workers; Snowden \& Hines, 1994). A considerable amount of research has shown that Latinos generally underutilize mental health services (e.g., Acosta, 1979; Alegria et al., 2002; Flaskerud \& Hu, 1992; Garland et al., 2000; Padgett, Patrick, Burns, \& Schlesinger, 1994b; Vega et al., 1998; Williams \& Collins, 1995). A study of the hospitalization rates of U.S. ethnocultural groups found that Latinos, when compared to Whites, underutilize outpatient mental health services and that they were less likely to be admitted to psychiatric services at nonfederal general hospitals and VA medical centers (Rosenstein, Milazzo-Sayre, MacAskill, \& Manderscheid, 1987). However, Latinos were more likely to be admitted to state and county mental hospitals than Whites. The research suggests that the prevalence of mental illness in Latinos is not necessarily uncommon and that economic concerns may be an important factor in determining the type of services Latinos are likely to seek.

\section{Premature Termination Rates}

Not only do Latinos have lower utilization rates than Whites, but they also have significantly higher rates of premature treatment termination (e.g., Sue, 1977). Wierzbicki and Pekarik's (1993) meta-analysis of the variables that account for premature treatment-termination rates indicated that minority racial status, low education level, and low socioeconomic status were closely associated with premature dropout rates. Although this comprehensive review did not specifically focus on Latinos, the results suggest that ethnocultural groups may be at risk for premature termination. Reports that specifically focused on Latinos also found low education and socioeconomic status to be closely linked to premature termination rates (U.S. Bureau of the Census, 1993). Research suggests, however, that the reasons for premature termination are more complex than low education level and low socioeconomic status. For example, Mexican Americans from low-income backgrounds reported that lack of benefit from therapy, self-perceived improvement, and environmental constraints (e.g., time off from work, financial costs, transportation) were influential reasons for leaving therapy (Acosta, 1980). Though some MexicanAmericans experienced dissatisfaction with the lack of benefit from therapy, it is encouraging that many endorse positive views about therapy and utilize services again if necessary (Acosta, 1980).

\section{BARRIERS TO COMMUNITY MENTAL HEALTH SERVICE UTILIZATION FOR LATINOS}

There are a number of socioeconomic, cultural, and psychotherapeutic factors that may help explain why Latinos underutilize mental health services and terminate prematurely from treatment. Investigation of these variables will provide insight into ways to develop responsive changes within the current community mental health care system to improve service delivery for Latinos.

\section{Socioeconomic Factors}

Many Latino families encounter socioeconomic challenges that place them at risk for living in poverty. National statistics on annual income indicated that $22.8 \%$ of Hispanics were living in poverty in 1999 compared 
to only $7.7 \%$ of non-Hispanic Whites. In $2000,6.8 \%$ of Hispanics aged 16 and older were unemployed compared to the lower unemployment rate of $3.4 \%$ for non-Hispanic Whites. Employed Hispanics were more likely to work in service positions and less likely to hold managerial or professional occupations than non-Hispanic Whites. Additionally, Hispanic workers earned less money than non-Hispanic workers. For instance, only $23.3 \%$ of Hispanics earned $\$ 35,000$ or more compared to the $49.3 \%$ of non-Hispanics with such earnings. Hispanics as a group have lower educational achievement than non-Hispanic Whites (U.S. Census Bureau, 2001b) and may have less work experience, yet reasons for differences in employment, income, and occupations are complex and not fully understood. Latinos with comparable skills relative to Whites often earn less pay for their work, which can result in Latino families being considered as the "working poor" (Santiago \& Wilder, 1991). Although many Latinos encounter serious socioeconomic challenges, research suggests that recent-immigrant Latinos may especially be at risk of poverty. For instance, in the Los Angeles area, recent Latino immigrants were mostly employed as low-end service workers, laborers, and operators while receiving low pay compared to other Latino workers (Catanzarite, 2000). In short, many Latinos come from disadvantaged socioeconomic backgrounds and are unemployed or work in low-end labor positions.

Latinos who come from low socioeconomic backgrounds are likely to encounter a number of challenges in utilizing treatment. Some of these challenges include limited availability of time to seek services, inability to afford services, and difficulties with transportation (Pumariega, Glover, Holzer, \& Nguyen, 1998). Many Latinos obtain temporary employment positions without any health benefits and it may then be too costly and difficult for them to take time off from work to attend their treatment sessions (Sandoval \& De La Roza, 1986). In fact, of all the ethnic groups in the United States, Latinos may be the least likely to have health insurance (Angel \& Angel, 1996; Berk, Albers, \& Schur, 1996). A recent report found that as many as $35 \%$ of Latinos did not have health insurance (Campbell, 1999). Furthermore, many Latinos who are uninsured not only have low incomes, but they are usually born outside of the United States and many have lived in the country for fewer than 10 years (Thamer, Richard, Casebeer, \& Fox-Nay, 1997).
Latinos without health insurance have been found to be less likely than insured Latinos to utilize health services regularly (Trevino, Moyer, Burciaga Valdez, \& Stroup-Benham, 1992). Also, youth identified to be in need of services have been reported to be less likely to receive services if they are not covered by their family's health insurance (Flisher et al., 1997). When individuals without health insurance need health services, they often seek services from community centers (Guendelman \& Wagner, 2000). Consequent1y, Mexican Americans are overrepresented in public mental health centers that cater to low-income populations (Martinez, 1988).

Hispanic women experience their own unique set of socioeconomic challenges. For example, unemployment rates for Hispanic women are higher compared to other women and Hispanic men (Amaro \& Russo, 1987; Canino, 1982). They also tend to have limited education, high fertility rates, and they are often single parents. In addition to these challenges, Hispanic women may have to work two jobs, making it difficult to carry out their family and household responsibilities (Canino, 1982). The cumulative psychosocial effects of these stressors may place them in need of mental health support. However, because of their socioeconomic constraints, many Hispanic women are likely to have limited or no time to seek out and utilize mental health services in their community.

Latino men may also undergo some of their own socioeconomic pressures and challenges. Whereas Whites in the United States tend to be more individualistic, allowing for the pursuit of their own goals, many Latinos have a collectivist attitude and may therefore be less likely to set goals that benefit themselves. Individualists learn to set goals and try to achieve them whereas collectivists engage in behaviors that do not call attention to themselves and work toward achieving harmony with others (Brislin, 1994). As a result of these differences in values, Whites may be more determined to progress in their careers, whereas some Latinos may remain more content at their current work positions and be less likely to pursue higher positions of employment in an effort to maintain peace with others. Also, the strong devotion to their coworkers may inhibit many Latinos from taking time off from work to receive mental health services.

In addition to the socioeconomic constraints that many Latino families endure, their surrounding com- 
munity may be limited in the quality and number of available mental health services. This is of particular concern because in $1980,40 \%$ of poor Latinos lived in poverty areas within inner cities (Santiago \& Wilder, 1991). Cheung (1991) discussed how the community surrounding the homes of Latino families influences the quality of available mental health treatment. In areas such as large metropolitan cities where there tend to be more economic resources, there is likely to be greater accessibility to mental health care and more affordable costs for treatment. Not surprisingly, treatment utilization rates are likely to be higher in areas with more resources. Similarly, in areas with limited resources, such as many ethnoculturally diverse communities, the available services may be difficult to access (Sandoval \& De La Roza, 1986). Additionally, mental health services in these areas may provide low-quality care, thereby reducing the likelihood that Latinos will want to utilize these services (Cheung \& Snowden, 1990).

Latinos may also be at a disadvantage when applying for treatment. In his review, Garfield (1994) presented evidence to support the claim that many treatment centers are selective in accepting individuals for treatment and that the centers' decisions have often been based on preference for individuals from high socioeconomic backgrounds. In addition to experiencing greater difficulties accessing and receiving mental health services, many Latino families from low socioeconomic backgrounds receiving services may be at risk for premature treatment termination. A study conducted in Los Angeles revealed that clients from lower socioeconomic backgrounds were more likely to receive fewer treatment sessions and have poorer treatment outcomes than clients from higher socioeconomic backgrounds (Sue et al., 1991). Another report examined a mental health clinic located in an area heavily populated with Mexican Americans from low socioeconomic backgrounds, and results indicated that $75 \%$ of admitted patients came for one interview, $15 \%$ for two interviews, and only $10 \%$ for three or more interviews (Kahn \& Heiman. 1978). Although other reports have also found an association between low social class and high premature treatment termination rates, the specific reasons for such a relationship are unknown (Berrigan \& Garfield, 1981). In short, there is research suggesting that the removal of socioeconomic barriers can lead to improvement in mental health service utilization (Norquist \& Wells, 1991;
Padgett, Patrick, Burns, \& Holzer, 1994a).

Some research on mental health service utilization, however, suggests the relationship between socioeconomic status and treatment attendance is unclear. One focus of Sue's (1977) comprehensive study was to investigate the mental health service utilization patterns of Latinos. After controlling for income and education, findings indicated that Latinos were more likely than Whites to prematurely terminate from therapy (Sue, 1977). Another study examined treatment utilization patterns in a sample of Mexican American women who were former clinic patients and were seen only by Hispanic therapists (Miranda, Andujo, Guerrero, Caballero, \& Ramos, 1976). Results indicated that women who discontinued therapy after the first session were more likely to be born in Mexico, agree less with White group norms, score high on external locus of control scales, and associate less with the White community. More importantly, socioeconomic status was not a significant predictor of treatment dropout. Other studies have shown socioeconomic status to be unrelated to treatment attendance (Garfield \& Affleck, 1959; Simons, Levine, Lustman, \& Murphy, 1984). Together, these results suggest that, for some Latinos, differences in cultural beliefs and values may be a stronger predictor of treatment attendance than socioeconomic status.

\section{Cultural Variables}

In addition to socioeconomic barriers, many culturally relevant factors have been shown to influence Latinos' perceptions about mental health and their utilization of mental health services.

Perceptions of Mental Illness. The influence of culture can play an important role in shaping one's view of mental illness. Specifically, Latinos' perception of mental illness may play an influential role in their underutilization of community services (Keefe, 1979; Sandoval \& De La Roza, 1986). For instance, many Latinos view physical symptoms more seriously than problems associated with mental health. Research has shown that Latinos are more likely to seek a physician's help for psychological problems (e.g., Acosta, 1979; Wells, Hough, Golding, Burnam, \& Karno, 1987). Comas-Diaz and Griffith (1988) indicated that symptoms of depression or anxiety may develop as a result of immigration and culture shock and, in turn, 
many Latinos are likely to perceive symptoms of depression and anxiety as physical problems. Furthermore, many Latinos seek help for their mental health concerns from their physician in an effort to avoid the stigma of seeing a psychologist (Gonzalez, 1997). Compared to Whites, stigma attached to psychiatric disorders seems to be more prevalent in Latinos and other ethnic groups (Alvidrez, 1999). Because Latinos may be more inclined to seek the help of a physician over a psychologist, treatment for their psychological difficulties will usually be medically based (e.g., pharmaceutical, intrusive medical procedures) and referral to a mental health clinic may not necessarily occur (Acosta, 1979).

"Fatalism." Another factor that may contribute to low mental health service utilization rates entails the notion of "fatalism," a belief typically shared by many Latinos (Chandler, 1979). Fatalism is the belief that individuals have minimal control over their environment. Instead, the environment controls an individual's life outcomes despite any efforts made (Comas-Diaz \& Griffith, 1988). Latinos who accept fatalism believe that events occur only as a result of luck, God's will, or harmful wishes made by their adversaries (Frevert \& Miranda, 1998). Therefore, Latinos who experience mental illness and believe in fatalism may be less inclined to seek help for their psychological needs.

Spirituality. Because many ethnocultural groups, including Latinos, endorse a collectivist perspective, they are likely to seek assistance from members of their own cultural group before seeking help elsewhere (Brinson \& Kottler, 1995). One example of how the collectivist perspective can serve as a barrier in receiving community mental health services is evident in Latinos' strong spiritual beliefs. One study revealed that individuals who endorse religious or supernatural causes of mental illness are less likely to utilize mental health services (Alvidrez, 1999). Some Latinos think that supernatural forces are the source of health problems and psychological distress (Altarriba \& Bauer, 1998; Frevert \& Miranda, 1998; Martinez, 1988). Because religion plays an important role in the lives of many Latinos, they often seek help for medical and mental health needs from religious organizations (Altarriba \& Bauer, 1998; Arredondo, 1991; Frevert \& Miranda, 1998). In fact, many Latinos may seek the assistance of spiritual leaders to help them resolve their daily problems regardless of acculturation level (Kreisman, 1975). Also, some Latinos will seek mental health assistance from folk healers (or "Curanderos"; Torrey, 1972). Curanderos are knowledgeable about folk medicine and are thought to be able to communicate with the spiritual world (Altarriba \& Bauer, 1998). These folk healers usually use power of suggestion, persuasion, direct advice, massage, herbs, rituals, prayer, and the client's sense of guilt and sin (Acosta, 1979). Although receiving assistance from a folk healer may be consistent with Latinos' cultural beliefs, it may not be common practice because the majority of Latinos live in urban areas, making it difficult for them to find folk healers (Keefe $\&$ Casas, 1980). The use of folk healers may be more common among those Latinos living in rural environments (Keefe, Padilla, \& Carlos, 1979), are Spanish monolinguals, are less acculturated, and come from low socioeconomic backgrounds (Keefe \& Casas, 1980; Madsen, 1964). Nonetheless, the use of folk healers and religious organizations may limit Latinos' utilization of community mental health programs.

"Familism." Another core component of the collectivist perspective shared by Latinos that may contribute to their underutilization of community mental health services is "familism" (Moore, 1970). Familism refers to an individual's strong identification, attachment, and loyalty to his or her family (Hovey \& King, 1996). Research has shown that Latinos endorse strong values of familism regardless of acculturation levels (Sabogal, Marin, Otero-Sabogal, Marin, \& Perez-Stable, 1987). In fact, irrespective of cultural orientation, the value of placing family first is higher for Latinos than for Whites (Keefe \& Padilla, 1987).

Family relationships are very close and are usually the first or main source of help for Latinos (Altarriba \& Bauer, 1998; Rogler, Malgady, \& Rodriguez, 1989). Latino family members provide strong support for each other at times of emotional and psychological difficulties (e.g., Cheung, 1991; Keefe et al., 1979; Madsen, 1964; Sandoval \& De La Roza, 1986). In fact, Latinos report high levels of satisfaction with the support they receive from their families (Sabogal et al., 1987). For Latinos, their families often provide them with self-worth and social support (Keefe et al., 1979). In addition, Latinos tend to value privacy highly (Frevert \& Miranda, 1998). Accordingly, many La- 
tinos may be reluctant to share their mental health challenges with people outside their family such as friends, counselors, and coworkers (Altarriba \& Bauer, 1998; Madsen, 1964). For many Latino families, it is a sign of weakness in character to experience mental illness (Keefe, 1982; Frevert \& Miranda, 1998) or to seek professional psychological help (Keefe, 1979, 1982). In fact, mental illness or experiencing psychological challenges carries a shameful stigma for many Latinos (Frevert \& Miranda, 1998) and some may even feel guilty for seeking help outside of the family (Altarriba \& Bauer, 1998). It is for these reasons that the majority of Latinos usually rely on familial support for help with emotional difficulties.

The strong Latino family system provides a supportive and accepting environment that may protect individuals from mental illness. Latino families may have greater tolerance for a family member with a mental disorder than non-Latino families (Martinez, 1993). Unfortunately, the acceptance of mental illness in a family member can result in not seeking treatment or in delays in doing so. When family is the only source of protection against mental illness, several negative consequences may result. For instance, Latinos with mental illness may develop an increasing dependency on others (e.g., family members) and experience the worsening of symptoms over time. Also, when Latino families are very cohesive and share much concern for each other, the emotional commitments of being a family member can yield additional stress for the individual experiencing mental health problems (Canabal \& Quiles, 1995). Additionally, Latinos whose families are not cohesive may experience stress because their family system is inconsistent with their ideal, well-integrated family system (Keefe et al., 1979). Finally, Latinos who do not have family members in the area may lack a strong substitute support network in times of stress (Keefe et al., 1979). Because many Latinos depend greatly on their families in times of psychological challenges and are dedicated to their churches, they may not see the value of using community mental health services when experiencing psychological problems, which in turn can contribute to their underutilization of services.

Cultural Commitment. The strength of the cultural commitment shared by Latinos may influence their preferences for treatment and willingness to seek community mental health services. One study showed that cultural commitment was related to preference for counselor ethnicity and willingness to use counseling services among Mexican American college students (Sanchez \& Atkinson, 1983). Moreover, findings revealed that Mexican Americans had individual differences in their preferences for the therapist's ethnicity. Although individuals from Mexican backgrounds with a strong commitment to their cultural heritage preferred a therapist of the same ethnic background, Mexican Americans who identified more with the host culture, both cultures, or neither culture, showed less preference for a therapist sharing their ethnicity. Similarly, in another study on Mexican American students' use of counseling services, stronger commitment to the Mexican American culture was associated with a preference for a Mexican American therapist who spoke Spanish (Sanchez \& King, 1986). Additionally, Sanchez and Atkinson (1983) found that Mexican American students with a strong cultural commitment to their culture showed the least willingness to self-disclose. A major implication of these findings is that cultural factors may inhibit self-disclosure and the use of counseling services in some Mexican Americans.

The generalization of the studies above to the Latino population is limited for several reasons including the use of college student samples who were not involved in real counseling sessions, the reliance on self-report surveys to assess outcome variables, and Mexican Americans being the only participants. Sears (1986) commented on the danger of making generalizations to the larger population based solely on research conducted on college students. College students and the general population can differ on a multitude of factors (e.g., age, language skills, education, test-taking experience, life experience, coping skills), which may ultimately have varying influences on individual's psychological well being (Sears). Mexican American college students are a select group and therefore the heterogeneity of the sample is limited compared to the larger and more diverse Latino population. Also, the use of counseling and self-disclosure in counseling may vary based on ethnic sub-groups (e.g., Puerto Rican, Cuban), generational status, and a host of other factors. Despite these limitations, the relationships of preference for counselor ethnicity and willingness to use counseling services with level of cultural commitment are worth noting and warrant further investigation. 
Language Proficiency. Language presents a number of challenges in the utilization of mental health services by Latinos and it is one of the most important cultural barriers to consider (Gaviria \& Stern, 1980; Wells et al., 1987). First, lack of language proficiency may limit Latinos' awareness of available mental health services in their communities, thus making it difficult for them to know where to seek needed services (Colon, 1996). Furthermore, although some Latinos may be aware of available services, they may not have the adequate resources to access them. For example, language issues can make it especially difficult for Latinos to utilize public transportation, obtain a driver's license, and comprehend the required paperwork at clinics (e.g., insurance, consent, clinic survey forms). Some Latinos may feel uncomfortable because of their unfamiliarity with the procedures involved in requesting services and may feel overwhelmed by the amount of paperwork they need to complete (Cheung, 1991). Additionally, since communication is essential to treatment, language barriers limit Latinos' ability to communicate with monolingual therapists and could contribute to dissatisfaction with services and premature treatment termination. Establishing therapeutic rapport with clients who have difficulties speaking English can be especially challenging because they are often spoken to in English only in formal settings (e.g., employment, legal matters, other relationships with authority). As a result, these individuals may enter therapy with the inclination to be distant and subservient, making a therapeutic relationship difficult to achieve (Russell, 1988).

Some ethnocultural groups may prefer receiving mental health services from bilingual therapists. Consistent with this suggestion, research has shown that Latino women who volunteered for therapy preferred therapy sessions to be conducted in Spanish (Boulette, 1976). Research has suggested that private or personal matters can best be expressed in one's native language (Marcos, Urcuyo, Kesselman, \& Alpert, 1973). Clients who prefer to speak in Spanish and who are allowed to express their emotions in Spanish can experience engagement and a sense of empowerment (Guarnaccia, De La Cancela, \& Carril1o, 1989). Thus, when clients who lack English proficiency skills are asked to communicate in English during therapy, they may not be able to fully express their feelings. Some therapists may even misinterpret these clients' awkward pattern of speech as symp- tomatic of a pathological condition (Russell, 1988). Consequently, these challenges can cause therapists to misunderstand, or not fully understand, important aspects of Latinos' communication styles (Sandoval \& De La Roza, 1986). Additionally, when clients cannot communicate effectively in therapy, they may be less likely to see the benefits of continuing treatment, thus resulting in premature termination. Although some community mental health services have bilingual staff, it is plausible that Latinos' negative language expectations in these settings prevent them from seeking out services altogether.

\section{Psychotherapeutic Challenges}

Some have argued that Latinos' perceptions of treatment for mental health problems contribute to their underutilization of services (Keefe, 1979; Torrey, 1972). Many Latinos may feel that mainstream mental health services cannot adequately address their specific needs and that non-Latino therapists may be insensitive to their psychosocial needs. Unfortunately, some of the relatively low percentage of Latinos who utilize mainstream mental health services may receive inadequate treatment. The use of mainstream counseling services by ethnoculturally diverse individuals has been suggested to be ineffective (Ibrahim \& Arredondo, 1986). Counseling and therapy developed out of a Eurocentric perspective and have been labeled "culture-bound" (Sue, Arredondo, \& McDavis, 1992; Sue \& Sue, 1990). With these considerations in mind, client-therapist interaction in Latinos will be examined. Client-therapist mismatching, particularly ethnocultural differences and psychotherapy expectations, can hinder positive rapport and effective treatment delivery. This can be a problem especially for Latino clients who see non-Latino therapists. In addition to challenges with client-therapist interaction, specific challenges Latinos encounter during assessment and treatment will be presented. Traditional treatment approaches (i.e., nondirective, future oriented) are often used with Latinos and these approaches may not be equally effective for all individuals. Therefore, special considerations should be placed on the specific and unique needs of Latinos.

Client-Therapist Interaction. Ethnoculturally diverse clients can encounter a variety of challenges in community mental health settings. For instance, 
therapists often prefer clients who are young, attractive, verbal, intelligent, and successful (Schofield, 1964). Some Latino clients, particularly those who experience language barriers and challenging socioeconomic conditions, may not share the characteristics preferred by therapists. Some of the stereotypes held about Latinos include poor hygiene and a lack of motivation and intelligence. The likability of the client is likely to influence treatment outcome (Garfield, 1994). For instance, therapists who hold negative views toward their clients may hinder treatment progress by inadvertently using words and displaying behaviors that express negative perceptions (Lorion \& Felner, 1986). Further support for therapists' negative perception of Latinos comes from an analog study examining White therapists' biases toward Hispanics (Arroyo, 1996). This study found therapists to have lower empathy toward Hispanic clients and to rate them as having poorer prognosis and greater blunted affect than White clients. As one would expect, the client's perception of the therapeutic alliance has also been shown to be a strong predictor of psychotherapy effectiveness (Bernal, Bonilla, Padilla-Cotto, \& Perez- Prado, 1998). Thus, the client's relationship with the therapist and the qualities of a positive relationship, such as trust and support, may play crucial roles in effective psychotherapy outcome. The interaction between client and therapist is clearly multifaceted and since it can strongly influence the effectiveness of psychotherapy, it is an important relationship to examine.

Some Latino clients may prefer working with a therapist from a similar ethnic background, whereas other Latino clients will not have such a preference. The issue of whether Latinos prefer therapists from similar ethnic backgrounds is therefore complex. There is empirical evidence that suggests that clienttherapist ethnic matching has no influence on client perceptions about therapist credibility, nor is ethnic matching always a preference for ethnically diverse clients. In one study, the ethnic background of therapists did not influence ratings of credibility given by Mexican Americans (Atkinson, Ponce, \& Martinez, 1984). Research has even shown that some Mexican Americans prefer an ethnically different counselor. For instance, Acosta and Sheehan (1976) examined the responses of junior college students to psychotherapists whose ethnicity and personal identification differed. Results showed that Mexican Amer- ican students expressed more positive attitudes (e.g., opinion of therapist's competence, trustworthiness, and understanding) toward the White therapist than the Mexican American therapist. In fact, many ethno-culturally diverse individuals have been reported to prefer counselors who have similar attitudes and values, have more education, are older, or have similar personalities over counselors who are of the same ethnicity (Atkinson \& Lowe, 1995). Lastly, ethnic matching between client and therapist may not be beneficial in trying to improve length of treatment use. For example, one study showed that having both ethnic and gender match between client and therapist did not decrease premature termination (Sterling, Gottheil, Weinstein, \& Serota, 1998). Also, Sue's (1988) review of psychotherapeutic services showed similar treatment outcomes for ethnoculturally diverse clients receiving treatment from culturally similar or dissimilar therapists. Together, these findings suggest that therapist ethnicity may not directly influence client preference, perceptions about therapist credibility, or treatment utilization patterns.

Contrary to some reports, research has shown that members of ethnocultural groups prefer therapists who are culturally similar to them. For example, Ponce and Atkinson (1989) found that regardless of acculturation level, Mexican American college students preferred ethnically similar counselors. Similarly, less acculturated Hispanic American college students have been reported to prefer ethnically similar counselors to White counselors (Pomales \& Williams, 1989). Research shows several benefits of ethnic matching on service utilization among Latinos. For example, a large-scale study in a county mental health system in California found that ethnic matching resulted in more outpatient visits and, perhaps more impressively, lower utilization of expensive inpatient emergency and skilled-nursing services (Jerrell, 1995). Another study with a large community sample in the Los Angeles area investigated the complexities involved in client-therapist ethnic and language match in better treatment outcomes (Sue et al., 1991). Results revealed lower dropout rates, longer treatment duration, and better treatment outcome for Mexican Americans matched with ethnically similar therapists. However, careful examination of the findings suggests that ethnic and language match was important only for Mexican American clients who did not speak English as their primary language. 
For years, there has been a widespread assumption that White therapists experience difficulties treating ethnoculturally diverse clients. As a result, a common belief exists that clients from various ethnic backgrounds may not benefit from therapy (Sue, 1988). Sue challenged this notion by stating that client-therapist ethnicity match is a distal variable to psychotherapy outcome. For instance, Sue (1988) noted that "in the treatment of ethnic minority clients, a therapist's knowledge of the client's culture is distal to outcome in the sense that the cultural knowledge must somehow be translated into concrete behaviors in the therapy session" (p. 306). Although Sue recognizes the importance of ethnicity, he also states that its meaning is more important. For example, although client-therapist ethnicity matching may exist, clients and their therapists may differ in their cultural values and life experiences. Conversely, clients and their therapists may also share similar cultural values and life experiences but differ in ethnicity (Sue, 1988). The inconsistency in the research literature on ethnic match between client and therapist may be due to therapist ethnicity being a distal variable. To better understand the relationship between client-therapist interaction and variables such as client satisfaction, treatment adherence, and treatment outcome, further research that examines more proximal variables such as client and therapist similarities in cultural values and beliefs, life experiences, and mannerisms are needed.

Assessment and Therapy Techniques. Issues such as client-therapist ethnic match, therapists' biases about clients, and language barriers may present challenges in the effective delivery of mental health services for Latinos. The lack of culturally responsive assessment methods and treatment approaches may also play a vital role in explaining the inadequate quality of service delivery to this population. Many therapists receive training primarily developed for the majority group and they may not be well informed about multicultural therapy issues. The use of culturally insensitive techniques when working with ethnoculturally diverse clients is likely to result in client dissatisfaction with services (Ruiz, Casas, \& Padilla, 1977; Sue \& Zane, 1987). This in turn may yield high rates of premature termination and poor psychotherapy outcomes with these clients.

Initial visits with mental health providers are likely to include some form of psychological testing. Many of the assessment instruments used in the United States are not culture-free or standardized on ethnic groups not fluent in English (Dana, 1995). Additionally, relatively few assessment instruments have been translated to other languages and fewer have established translation equivalency (Obazaki \& Sue, 1995). As a result, the utility of many of these instruments to ethnically diverse clients may be limited. Fortunately, some commonly used assessment measures have been translated into Spanish and have had their psychometric properties examined. For example, the Spanish version of the Beck Depression Inventory has been shown to have good psychometric support for assessing depressive symptomatology in Spanish-speaking individuals (Bonicatto, Dew, \& Soria, 1998). Also, the Spanish version of the Personality Assessment Inventory has been suggested to be useful with monolingual and bilingual Hispanics (Rogers, Flores, Ustad, \& Sewell, 1995). Additionally, there is a standardized Spanish version of the Minnesota Multiphasic Personality Inventory-2 (Graham, 2000). Nonetheless, there are many psychological assessment measures that do not have standardized language translations or norms for specific ethnic groups. Also important to note is that training in psychological assessment often does not include culturally sensitive ways of administering tests (e.g., appropriate interpersonal interactions with ethnoculturally diverse clients; Dana, 1995). An unfortunate result may be the misdiagnosis of some Latinos and other ethnically diverse clients.

The mental health system often does not adequately address the needs of some ethnoculturally diverse individuals from the beginning of treatment services. Latino clients, especially those that are Spanish monolingual, may feel uncomfortable with traditional assessment techniques and may experience difficulty completing some measures. Therapists should inquire about Latino clients' history of test taking (Velasquez $\&$ Gonzales, 1997). For instance, clients who are recent immigrants and Spanish monolinguals, who have low levels of education, and who have limited experiences interacting with a mental health system are likely to experience difficulties understanding the purpose of the assessment measures and accurately completing the measures (Velasquez \& Gonzales). Since many Latinos endorse views of mental illness that contrast with those of the majority group, an awkward assessment experience may further contribute to their skepticism of mental health services. Therefore, Latinos' 
dissatisfaction with assessment techniques coupled with their varying views of mental illness and skepticism of mainstream mental health services may influence many of them to terminate prematurely from treatment or even influence some to not accept treatment services at all.

In addition to problems in assessment, there are also challenges in providing treatment to the Latino client. Since the development of culturally sensitive therapies that are empirically supported has only recently been encouraged (Nagayama Hall, 2001), many clinicians may rely on treatment approaches that have been empirically validated only on Whites. When empirically supported treatments are used with diverse ethnic groups without proper evaluation, a serious disservice may be done to many clients. Unfortunately, since empirically supported therapies are usually investigated with Whites, their external validity is subject to question. Therefore, it is unlikely that using these therapies with ethnically diverse clients will constitute a culturally sensitive therapeutic approach (Bernal \& Scharron-Del-Rio, 2001). For a more comprehensive understanding of empirically supported therapies for ethnically diverse clients and recommendations for how to advance the knowledge of effective culturally sensitive therapies, please see Bernal and Scharron-Del-Rio.

There may be a disagreement between the values in mainstream psychotherapy and values of the Latino culture (Padilla, Carlos, \& Keefe, 1976). For instance, prior reports suggest that Latinos prefer a more directive and formal approach to therapy than a nondirective approach that is often used by therapists (e.g., Cherbosque, 1987; Kunkel, 1990; Ponce \& Atkinson, 1989; Sue \& Zane, 1987). This preference is even evident in Hispanic college students regardless of acculturation level (Pomales \& Williams, 1989). Furthermore, Cherbosque's (1987) study of Mexican and American college students revealed that Mexicans expect less openness from therapists and more openness from clients than White European Americans do. Many Latinos share a linear orientation to therapy and expect therapists to provide specific directions to follow (Sandoval \& De La Roza, 1986). Additionally, it has been suggested that in their daily lives, Latinos focus on the present instead of being past or future oriented (Casas \& Vazquez, 1989). As a result, most Latinos prefer therapy to focus on the present and not on the future, which is generally the orientation of mainstream therapy (Sandoval \& De La Roza, 1986; Sue \& Zane, 1987). Furthermore, many Latinos are more concerned with the alleviation of their symptoms and problems than with long-term plans on personal change. Mainstream therapy, however, typically focuses on helping the client plan for the future and develop long-term goals (Sandoval \& De La Roza, 1986). In summary, many Latinos prefer therapy to be brief, direct, and problem-focused (Sue $\&$ Sue, 1990). Because mainstream mental health programs generally provide services that are in contrast to Latinos' preferences and expectations of therapy, many Latinos may decide to not seek mental health services.

\section{CLINICAL CONSIDERATIONS: IMPROVING THE DELIVERY OF COMMUNITY MENTAL HEALTH SERVICES TO LATINOS}

Many barriers to community mental health services for Latino families and challenges in the delivery of these services have been presented. Community mental health programs should focus on closing the gap between the need for mental health services and the underutilization of these services. Services need to be more available and accessible to Latinos, and mental health care practitioners need to be culturally competent. To improve the accessibility and effectiveness of community mental health services to Latinos, efforts to reduce the existing socioeconomic, cultural, and psychotherapeutic barriers are needed.

\section{Increasing Accessibility of Services}

The low socioeconomic conditions of many Latino families are likely to present challenges in obtaining mental health treatment. Therefore, special efforts need to be made to better provide Latino families with more accessible mental health care. By increasing the accessibility of services in areas heavily populated with Latinos, many individuals may be more inclined to use these services. Equally important is increasing the accessibility of mental health services in areas where there are relatively few Latinos. Latinos in these areas may have limited social support and there may be few Latino clergy or folk healers in the area from whom families can seek help. 
There are several ways to increase the accessibility of community mental health services to Latino families. Because the majority of Latinos are considered to be members of the working class, community services can offer flexible hours and appointments (Leong, Wagner, \& Tata, 1995), such as extending their business hours to include evenings and weekends. However, some Latino families may not have adequate transportation to attend services away from their home. As a result, community mental health programs should also be encouraged to locate in Latino communities or areas that are near Latino communities and are easily accessible by public transportation. Programs that are not in or near Latino communities can arrange transportation for their clients (Leong et al.) or provide informational workshops in the Latino community about using public transportation to arrive at the centers. Additionally, Latino women may be especially inhibited from seeking services due to their responsibilities of watching their children. Community mental health centers should be encouraged to offer childcare services to better enable mothers to receive mental health treatment (Leong et al.).

\section{Increasing the Dissemination of Information About Services}

Although extending business hours, being more conveniently located, and providing childcare services may potentially improve the accessibility of the community mental health programs, utilization rates may not change until the surrounding Latino communities are aware of the, changes. An active effort to distribute information about available mental health services can ultimately help to increase awareness in the community (Alvidrez, 1999; Keefe \& Casas, 1980). Once Latinos become aware of culturally sensitive mental health services and begin to utilize them, they may find them helpful and continue to use them (O’Sullivan \& Lasso, 1992). In addition to educating the Latino community about the convenient community mental health services, Latinos can also benefit from learning how to identify mental illness, how mental health services can treat mental illness, and the importance of taking an individual with a mental illness to receive mental health care. By improving their knowledge of mental illness and its treatment, Latinos may be more likely to utilize needed services.
Useful suggestions of how to disseminate information about services are needed. There are a variety of places where the dissemination of information about mental health services can occur. Some practical community locations are clubs, associations, and religious organizations (Colon, 1996). Additionally, mass mailing of the information might also prove helpful in disseminating information to Latinos in the community. The distributed information needs to be culturally relevant and informative. There should be a special emphasis on reaching out to individuals from low socioeconomic and non-English-speaking backgrounds (Keefe \& Casas, 1980). One way of doing so is to hire a Latino ombudsman to help establish trusting ties between community mental health services and the Latino community. The ombudsman could publicize the available mental health services to the community. This could be especially beneficial in communities with a high proportion of immigrants, nonEnglish speakers, and members of low socioeconomic status because these individuals may not be aware of available mental health services and the minimal cost of some of these services (Keefe \& Casas). By making the suggested changes and educating Latino communities about the improvements, more Latinos can become aware of the availability and accessibility of community mental health services.

Although a lack of familiarity with available services may serve as a utilization barrier, there are other reasons why Latino families underutilize needed mental health services. In one large-scale study, respondents were asked about their needs for mental health services, the barriers they perceived to getting the services, and their use of services (Stefl \& Prosperi, 1985). An important finding was that the underutilization of mental health services by Latinos was not primarily due to being unaware of the available services or not knowing the location of services. Rather, it was due to not knowing that some of these services are available at little or no cost. Only some Latinos, including those who speak only Spanish, have low education backgrounds, are recent residents, and may be unfamiliar with available mental health services (Keefe \& Casas, 1980). Perhaps, then, stronger efforts to disseminate information about the low cost of community mental health programs may increase the utilization of such services by Latinos. 


\section{Increasing Awareness among Mental Health Practitioners}

Increasing awareness among therapists about the Latino culture and how to provide Latinos with better mental health care may help to minimize errors in the assessment, diagnosis, and treatment of Latino clients. It is especially important for mental health care practitioners to be culturally competent because cultural issues can play an integral role in treating clients. It is unfortunate that some therapists have strong biases against ethnically diverse clients (Wampold, Casas, \& Atkinson, 1981). Therapists should avoid assuming that Latino clients are poor prospects for therapy (Russell, 1988) and they should acknowledge and accept their own "cultural baggage" (Ibrahim, 1985).

The preexisting stereotypes that non-Latino therapists may have about Latinos can be reduced in several ways. Therapists should carefully consider how their cultural beliefs influence their perceptions of Latino clients as well as their choice of therapeutic practices with Latino populations. The optimism and empathy of a therapist toward a client are factors that are necessary in the therapeutic process and may even influence the outcome of therapy (Arroyo, 1996). Therefore, rather than labeling Latino clients as those who will not benefit from therapy, therapists should make extra efforts to be sensitive and flexible to their clients' needs (Russell, 1988). They should interpret a client's behavior on the client's values rather than their own (Casas \& Vasquez, 1989; Ibrahim \& Arredondo, 1986). For example, therapists should learn why Latino clients have a tendency to self-disclose at a slower rate than that of most clients. Their slow self-disclosure may be a reflection of cultural norms and therapists should be cautious in interpreting client behavior as resistance or defensiveness (Padilla et al., 1975). Some Latino clients may avoid eye contact with the therapist in an effort to convey respect and admiration toward the therapist. The therapist should be cautious in interpreting poor eye contact as a sign of resistance and may want to avoid efforts to maintain eye contact with these clients (Padilla et al., 1975). Also, Latino clients may find it normal to discuss their well being in relation to the well being of their families, whereas the majority group may be more concerned with how well individuals are doing independent of their families. Thus, differences in how Latinos think and act with respect to their families should be viewed in their perspective, and therapists' views of interdependence in relation to mental illness should not bias their acceptance and understanding of the Latino client.

It seems logical to assume that the more knowledge that mental health practitioners have about the Latino culture, the better they can be in providing treatment to their Latino clients. However, there is no research that assesses whether multicultural counseling education leads to better treatment outcome in ethnoculturally diverse clients (Atkinson \& Lowe, 1995). Due to the paucity of research in this area, it is not possible to rule out that teaching therapists specific information about various ethnic groups and cultures may actually increase the likelihood that therapists will stereotype their clients according to what they have been taught (Sue \& Zanc, 1987). Although therapists should be competent in multicultural issues, emphasis should be placed on exercising caution and refraining from stereotyping their clients, and therapists should be reminded constantly to view their clients as unique individuals. Instead of strictly relying on what they have been taught about various cultures, therapists should take an avid interest in learning about their client's culture. Therapists can ask clients questions about their culture to determine the influence that cultural beliefs and values may be having on the client's problem. Every client is unique in many ways, such as their symptom expression, social functioning, and history of problems; their cultural background is no exception.

Because having knowledge of multicultural issues may be beneficial to therapists, training programs should require courses in multicultural education and promote experiences that help therapists learn about assessment methods and intervention techniques that are culturally sensitive to various ethnic groups (Aponte \& Crouch, 1995). It appears that graduate clinical/counseling training programs are implementing multicultural courses at a rapid rate and that these courses include both experiential and didactic learning opportunities (Ponterotto, 1997). Integrating multicultural fieldwork experience in the curriculum is essential to training counselors to be culturally competent (Porter, 1994). Direct contact with ethnically diverse clients during training call help students learn how to interact successfully with the clients (McRae \& Johnson, 1991). Another way for students to learn 
more about the Latino culture and how to treat Latino clients effectively is by interacting with Latino faculty and students, as well as non-Latino faculty with expertise in multicultural counseling. These individuals can share knowledge and experiences that can prove beneficial to students learning about Latino culture.

Training should ensure that therapists are knowledgeable about the importance of religion, family, and acculturation experiences in the lives of Latinos. Many Latinos have strong religious values and some seek help from clergy for their mental health needs. Because of the importance of religion in the lives of many Latinos, therapists should try to understand how the Latino client's religious beliefs are related to the presenting problem and should aim to develop a treatment plan that incorporates the client's spirituality (Guarnaccia, Parra, Deschamps, Milstein, \& Argiles, 1992). Mental health professionals also need to be cautious to not provide information or treatment that is inconsistent with the cultural or religious beliefs of Latinos. Following these recommendations can help treatment be more culturally sensitive, and the Latino client may potentially view the therapist as being more competent.

When therapists are well educated about the Latino culture, they can also better understand the supportive role of family members (Acosta, 1984; Rogler et al., 1989) and the potential benefits for Latino clients of incorporating the extended family in treatment plans (Keefe \& Casas, 1980; Padilla \& De Snyder, 1985). Since family may especially be important to the Latino client, therapists need to exercise special caution when discussing mental illness with the client's family members. The therapist needs to inquire about the family's conception of mental illness and should present information cautiously to family members in such a way that acknowledges and builds on the conception shared by these families (e.g., view of mental illness on a continuum). Furthermore, therapists should always strive to communicate an understanding of the concerns shared by ethnoculturally diverse clients in such a way that these individuals are encouraged to attend mental health services (Brinson \& Kottler, 1995).

Therapists should also understand the challenges Latinos experience in immigration and acculturation (Keefe \& Casas, 1980). To have a good understanding of these experiences, therapists need to acknowl- edge the unique life experiences of Latino families. After all, most Latinos living in the United States do not share the same life experiences as Whites. They often encounter unique external stressors which may include having less power, voice, and opportunity than Whites (Casas \& Vasquez, 1989). These varying experiences can play an important role in the development of mental health problems as well as in their treatment progress. Therapists can become better educated about these issues by working closely with Latino supervisors, mentors, and classmates during their training. Therapists should also learn to apply their knowledge of Latinos' life experiences by having Latino clients during their training. Additionally, therapists who assess a Latino client's acculturation status and know how to modify treatment modalities to better fit the client can provide more culturally sensitive treatment. For instance, Latinos who are highly acculturated may benefit from treatment using universally accepted clinical methods. In contrast, Latinos who are less acculturated may benefit more from modified treatment that is more consistent with their culture (Rogler, Malgady, Costantino, \& Blumenthal, 1987). Ultimately, understanding the Latino client's culture and experiences of unfairness in society can better guide therapists to providing culturally sensitive treatment.

Further insight regarding how best to provide Latinos with culturally sensitive treatment can come from observing how Latino clinicians interact with Latino clients. One recent study investigated how Latino clinicians treat Latino clients (Manoleas, Organists, Negron-Velasquez, \& McCormick, 2000). Latino clinicians were most interested in treatment goals that related to empowerment, stress reduction, coping skills, reducing family problems, and decreasing isolation. Goals that relate to acculturation and transference issues did not seem to be as important to Latino clinicians in helping their Latino clients. It seems important for the Latino clinician to have a strong advocacy role and to help strengthen the client's family's ability to cope. Also, a great majority of Latino clinicians reported using the same modes of treatment with their Latino and non-Latino clients and desired to meet with Latino clients for one session a week. However, Latino clinicians preferred to have closer contact with and more self-disclosure to Latino clients than they did with non-Latino clients, probably because Latino cli- 
ents prefer to have a close relationship with their therapist. One simple suggestion to help therapists achieve a closer relationship with Latino clients is to sit more closely with them than they would with clients from other ethnic groups (Padilla et al., 1975). The study of Latino clinicians found that if Latino clients missed appointments, clinicians were likely to make effort to inquire about their absence by contacting the client's family members and friends (Manoleas et al., 2000). This study suggests that many Latino clinicians use universally accepted clinical methods in treating Latino clients, but have a closer and more open relationship with the client. The rapid population growth of U.S. Latinos combined with the limited availability of Latino clinicians warrants the need ,to educate and train clinicians to be competent in treating Latino clients. The non-Latino therapist who is experiencing challenges in treating a Latino client should consult with a therapist with a knowledge of the Latino culture, provided the client gives permission to do so (Arredondo, 1996).

Another rich source of information about better providing Latinos with culturally sensitive treatments can come from receiving input from the Latino community when developing new mental health programs (Keefe \& Casas, 1980). By involving the Latino community during the planning phase, the new services can be created to become more culturally responsive to the needs of Latinos in nearby communities. Also, once the programs have been developed, communication between the Latino and professional communities should remain active (Colon, 1996). As a result, Latinos may be more likely to utilize the services.

\section{Increasing Awareness among Physicians and Clergy}

Mental health services for Latino families can further be improved by making changes in Latinos' current sources of treatment outside of the family. Because members of the Latino community may seek the assistance of physicians before seeing mental health professionals for their mental health concerns, efforts should be made to provide additional mental health training to physicians so they can better identify and refer patients with psychological problems to appropriate mental health professionals. When referring patients to mental health services, physicians should take into consideration which services meet the individual family's needs such as affordability, accessibility, and language barriers that might be present. Since many Latinos seek mental health service from physicians, it is important that physicians are well informed of the available community mental health services. Therefore, mental health agencies should provide thorough information (e.g., pamphlets) to physicians about available services in the community. These include, but may not be limited to, information on cost, specific types of services offered, and accessibility.

Latinos may also seek help for their mental health concerns from clergy. Thus, a similar effort towards better educating clergy about psychological issues could help to better address the mental health needs of Latinos (Acosta, 1979). Furthermore, it may be helpful to disseminate information about how religious and psychological views of mental illness need not be competing views. Mental health programs should be encouraged to incorporate some religious values or practices into their services to Latino families (Alvidrez, 1999). If mental health programs acknowledge and incorporate the religious beliefs and values of Latinos into the services they offer, the help they provide can serve as a continuum of care for Latino families, as opposed to a service that is independent of their preferred source of help.

\section{Improving Client-Therapist Verbal Communication}

Barriers in providing mental health services can further be reduced by employing more Spanish-speaking professionals and staff in mental health programs (Keefe \& Casas, 1980). One way to achieve this would be to train more Latinos in mental health disciplines. The number of ethnoculturally diverse psychologists in the United States is much fewer than one would expect based on their representation in the population (Jenkins \& Ramsey, 1991). In fact, reports indicate that in 1993, there were only about 500 bilingual therapists and counselors in the United States. (Munoz \& Ying, 1993). These low numbers highlight the urgent need for more bilingual therapists. Bilingual therapists should be encouraged to work in community mental health centers and other bilingual staff should be encouraged to pursue higher employment positions. Furthermore, therapists and staff 
who do not speak Spanish could be given incentives for learning to speak the language. Training programs may consider offering a Spanish language course that is specifically designed to teach therapists vocabulary that is useful and commonly used in clinical settings. Additionally, the use of other bilingual workers in the community to assist in treating a bilingual client may be beneficial (Acosta, 1979). For example, after a bilingual interpreter program was developed in a psychiatric clinic, the percentage of Spanish-speaking patients admitted to the clinic doubled (Acosta \& Cristo, 1981). These trained interpreters were knowledgeable of key psychotherapy concepts and nomenclature used in the clinic and they proved to be helpful in translating the meanings of what patients said in therapy to English monolingual therapists.

Bilingual community workers such as interpreters may be helpful in facilitating therapy sessions. Therapists should, however, take several steps of caution when using interpreters to ensure an effective partnership. Parker (2000) provides several suggestions to improve the effectiveness of using an interpreter in the therapy setting. First, it is important to use qualified interpreters and to avoid using the client's children, relatives, or friends. The use of family members or friends as interpreters can result in the Latino client experiencing feelings of shame and embarrassment when disclosing personal problems. Moreover, the use of children as language interpreters in the clinical setting can foster parent-child power imbalances, which can potentially disrupt family unity. Also, since qualified interpreters have some knowledge of psychological concepts, they can provide more accurate translations than family members or friends. Parker also suggests the therapist make sure the client approves of the interpreter. It is important for the therapist to speak directly to the client and avoid talking to the interpreter. Because certain phrases may not translate well into Spanish, the therapist should be prepared and able to rephrase statements. It is also helpful to make sure interpreters are simply translating and not providing their opinion or insight. Finally, these cautionary steps are important because the client's judgment of the therapist's skill can be influenced by the quality of the interpreter. By following the guidelines proposed by Parker, therapists can help to ensure the use of trained interpreters will improve the communication between themselves and their monolingual clients.

Research suggests that the use of bilingual interpreters helps increase service utilization in Latinos. However, the psychotherapy outcome effectiveness of bilingual therapists in relation to interpreters remains unclear. Conceivably, the utility of bilingual therapists and interpreters may vary depending on the presenting issue (e.g., family counseling, work-related challenges) and the type of mental health service provided (e.g., assessment, counseling, intake). Further research and enhanced understanding in this area will enable mental health professionals to assess the appropriateness of using bilingual interpreters in the clinical setting with Latinos.

\section{Improving Assessment Techniques}

Language barriers and other cultural differences can be obstacles during the assessment of a Latino client. Although many assessment measures have psychometric support, not all measures have good normative data on individuals from various ethnocultural groups (Dana, 1995; Marin \& Marin, 1991). Only assessment measures that have been standardized on individuals of various ethnocultural backgrounds should be used when assessing clients from diverse ethnic backgrounds. For assessment instruments that are available in English and Spanish, carefully selecting the version to administer to the client can increase the validity of the test results. For example, selecting which language version of the MMPI-II (English or Spanish) is appropriate for bilingual clients should be based on the language the client uses to express emotional content (Sue \& Sue, 1999). It should also be noted that simply adapting and translating assessment instruments into Spanish is not necessarily a solution to invalid testing, as the language translation of an instrument has commonly been shown to result in changes in the internal structure of the instrument (Marin \& Marin). Therefore, it is important for researchers rigorously to evaluate the psychometric properties of the Spanish translations of assessment tools to help practitioners gain a better understanding of the appropriate measures for use with culturally diverse clients. Additionally, researchers have highlighted the need to develop valid assessment instruments designed specifically for use with Latino populations (Carlo, Carranza, \& Zamboanga, 2002). 
For the present time, clinicians should use multiple sources of information when treating cross-cultural clients in an effort to minimize errors in assessment (Goldstein, 1981). For example, in addition to using standardized assessment measures, therapists should obtain a comprehensive psychosocial history, a mental status examination, and any other relevant information, such as a family interview (Velasquez \& Gonzales, 1997). By using multiple assessment methods, the likelihood of misunderstanding the client as a result of poor verbal abilities is lessened (Ibrahim \& Arredondo, 1986). Finally, therapists need to use caution when interpreting the assessment results of ethnoculturally diverse clients to avoid over- or under-pathologizing (Obazaki \& Sue, 1995). The unbiased interpretation of assessment results for these clients is possible only when therapists are knowledgeable and sensitive to multicultural issues and use culturally appropriate assessment instruments.

\section{Increasing Treatment Adherence}

Low treatment attendance and high rates of premature termination are of particular concern for Latinos. When clients begin to miss psychotherapy appointments, it may be indicative of financial challenges or dissatisfaction with the services. Sessions following missed appointments should discuss the reasons for missing the previous session and the client's possible feelings of dissatisfaction in psychotherapy (Berrigan \& Garfield, 1981). The client may have also missed a session as a result of attending to a family emergency. In an effort to avoid devaluing the importance of family to the Latino client, the therapist should acknowledge and, if appropriate, reinforce the client's decision. The therapist may also learn the client is dissatisfied with some aspect of therapy such as treatment goals, therapy style, or progress. Discussing these issues may help to guide appropriate changes in the psychotherapy process and consequently may increase the therapeutic alliance and improve the client's therapeutic outcome.

Treatment adherence may also be improved by providing Latinos with culturally sensitive treatment and by informing them of what to expect from therapy before they enter the therapeutic process (Organista, Munoz, \& Gonzalez, 1994). Because the assess- ment process can be awkward for some Latinos, one way to better prepare Latinos for what to expect is to explain to them that the assessment procedures as well as receiving feedback about the results is an important and necessary component of the therapeutic process (Velasquez \& Gonzales, 1997). Also, many Latino clients may expect therapy to only last one session or may believe that once a specific mental health concern is resolved therapy is no longer necessary despite the presence of other mental health concerns (Gonzalez, 1997). Therefore, therapists need to educate Latino clients on how long therapy may last and why such a length of time is necessary. These suggestions aim to make clients more comfortable and satisfied with therapy, which in turn could increase their treatment adherence.

\section{Using Culture-Centered Counseling and Ethnic-Specific Mental Health Programs}

Because of the challenges inherent in treating the mental health needs of Latino clients, it may be beneficial to use a culture-centered approach. Culturecentered counseling attempts to understand the culturally learned expectations and values of individuals in order to better understand and evaluate their behaviors (Pedersen, 1994). When interpreting the client's behavior, the clinician should remember that similar behaviors often have different meanings across cultures (Pedersen, 1994). In addition to being familiar with culturally learned expectations and values, culture-centered counselors need to have the skills to help address the problems of clients from various cultural backgrounds (Pedersen, 1988). A counselor who is culturally responsive is one who not only acknowledges the client's ethnicity and culture, but also demonstrates knowledge, interest, and an appreciation of how the client's problem fits into a cultural context (Atkinson \& Lowe, 1995). Mexican American clients have been shown to provide higher ratings of counselor credibility and cultural competence to culturally responsive counselors than to culturally unresponsive counselors (Atkinson, Casas, \& Abreu, 1992). This finding was not affected by client acculturation or counselor ethnicity. Additionally, a counselor who is aware of cultural assumptions, knowledgeable of cultural facts and information, and has the therapeutic skills to make a difference can 
make more accurate diagnoses and provide more accurate treatment for individuals from varying ethnocultural backgrounds (Pedersen, 1994). A culturally skilled mental health professional must have a constant and ongoing commitment to change in awareness, knowledge, and skills (Sue, Arredondo, \& McDavis, 1992).

Over 20 years ago, the Division of Counseling Psychology of the American Psychological Association established the specific characteristics of a culturally competent mental health professional (Sue et al., 1982). Since that publication, many contributions have been made toward defining and developing cultural competence among mental health professionals (e.g., American Psychological Association, 1993; Arredondo et al., 1996; Sue, 2001; Sue, Arredondo, \& McDavis, 1992; Sue et al., 1998); and interested readers are encouraged to seek out these sources. Cultural competence has received much attention in the delivery of mental health care services for Latinos and has become especially important because of its effectiveness in treatment outcome with the Latino population (Paz, 2002). Because there have already been two decades of effort devoted to establishing cultural competence standards (e.g., a therapist's awareness of his or her own assumptions, values, and biases), training programs are encouraged to provide classes that teach students about racial/cultural issues in an effort to assist students in developing cultural competence (Carter, 2003). For information about teaching students to become racially and culturally competent, please see Carter (2003). Although many publications have contributed to our understanding of cultural competence, an urgent and important issue in Latino mental health services research that has received minimal attention is the careful examination of the effectiveness of culturally competent services (Vega \& Lopez, 2001).

Some psychotherapy outcome research has examined the use of traditional psychotherapy approaches with Latinos. Organista, Munoz, and Gonzalez (1994) investigated the effectiveness of cognitive-behavioral therapy for depression in low-income and minority medical outpatients (44.4\% of participants were Spanish-speaking Latinos). Cognitive-behavioral therapy was effective in reducing depressive symptomatology scores; however, the results of this study were not as effective as those found in prior reports. Although cognitive-behavioral therapy was effective in reduc- ing depressive symptoms in this diverse medical population, some cultural modifications to the therapy approach could improve treatment effectiveness. As such modifications are made, it is important to examine how specific cultural modifications and specific treatment components are associated with treatment outcome (Lopez, 2002).

Research has begun to evaluate the treatment effectiveness of traditional psychotherapy approaches that have been modified according to cultural values. For example, in a study with depressed Puerto Ricans, both cognitive-behavioral therapy and interpersonal psychotherapy were shown to be effective treatments (Rossello \& Bernal, 1999). It should be noted that both methods of treatment were modified to take into consideration cultural aspects of Latinos (e.g., familism). Based on recent research, the applicability of traditional psychotherapy approaches with various Latino groups appears most promising when appropriate modifications are made in an effort to make psychotherapy more culturally sensitive. One such example is including the families of Latinos with schizophrenia in social skills training sessions that were originally developed for patients only (Kopelowicz, 1997). Furthermore, Nagayama Hall (2001) urges researchers and clinicians to modify empirically supported treatments to become culturally sensitive therapies. The alternative to modifying empirically supported treatments or traditional psychotherapy approaches to best fit the needs of Latino clients is to develop entirely new psychotherapy approaches that are consistent with the norms, values, and beliefs of the Latino culture (Rogler, Malgady et al., 1987). Though the method of developing these therapies may vary, it is certain that culturally sensitive and empirically supported psychotherapies for Latinos are urgently needed. For information on how research collaboration between culturally sensitive therapies and empirically supported therapies can help develop effective psychotherapy with ethnically diverse individuals, please see Nagayama Hall (2001).

Although using therapies that are both culturally sensitive and empirically supported is ideal, there are relatively simple modifications in traditional psychotherapy techniques that can be made to help provide more culturally sensitive treatment for Latinos (Organista et al., 1994). One way to introduce the client's culture into traditional psychotherapy is to use a lan- 
guage-switching technique (Pitta, Marcos, \& Alpert, 1978). With this technique, traditional psychotherapy methods are not altered. Rather, the therapist encourages clients to use their native language when talking about emotional expression to minimize possible defensiveness, Another way to integrate elements of the Latino culture with traditional psychotherapy is to acknowledge folk treatment during the psychotherapy process (Kreisman, 1975).

Therapy with the Latino client should limit the use of a person-centered approach because of Latino clients' cultural values and preferences in therapy (e.g., collectivist perspective). Most Latinos expect therapy to be directive (Kunkel, 1990) and actually prefer directive therapy (Borrego, Chavez, \& Titley, 1982; Ponce \& Atkinson, 1989). Treatment that is brief and problem oriented may be more suitable than longterm treatment plans for many Latinos. The use of group therapy (Malgady, Rogler, \& Costantino, 1990; Acosta, 1982), particularly family therapy (Padilla \& Salgado de Snyder, 1985; Rogler, Malgady et al., 1987; Szapocznik et al., 1989) may also be helpful to some Latino clients. By being in a group with culturally similar individuals, Latino clients may feel more accepted and comfortable. This in turn may make Latino clients more willing to share their thoughts and feelings in therapy (Altarriba \& Bauer, 1998). Since some Latino clients may still self-disclose at a slow rate, therapists should remain patient and accepting of their clients' pace. Following these suggestions can help therapists increase the effectiveness of therapy for their Latino clients.

In an effort to provide more culturally sensitive services to Latinos, many ethnic-specific mental health programs are being implemented in communities. Ethnic-specific programs are likely to have more occurrences of ethnic match between therapist and client than mainstream programs. More importantly, compared to mainstream programs, ethnic-specific programs and staff are more likely to have better knowledge of cultural values and beliefs, thus they can provide treatment that is more culturally sensitive to the specific needs of Latino clients (Flaskerud, 1986). In contrast to ethnic-specific programs, conventional treatment programs often use well-established methods of treatment on ethnically diverse individuals. These conventional methods of treatment are based on the assumption that they generalize to all ethnic groups; however, this may not always be the case.

Research on the effectiveness of ethnic-specific programs shows promising results. Studies show that ethnic-specific programs help to improve the accessibility and utilization patterns of services for ethno-culturally diverse individuals (Akutsu, Snowden,, 8. Organista, 1996; Snowden, Hu, \& Jerrell, 1995; Takeuchi, Sue, \& Yeh, 1995). Takeuchi et al., for example, compared a diverse ethnic group of adults from ethnic-specific and mainstream mental health programs on return rate, length of treatment, and treatment outcome. After controlling for ethnic match and several demographic variables including gender, age, psychiatric disorder, and Medical eligibility, Mexican Americans were 11 times more likely to return to ethnicspecific programs than mainstream programs. Also, the length of treatment for clients was significantly longer in ethnic-specific programs than mainstream programs. Furthermore, Mexican Americans who entered ethnic-specific programs, regardless of match, were more likely to return for treatment and remain in treatment for more sessions than Mexican Americans who entered mainstream programs. Therefore, it is apparent that there are aspects of ethnic-specific programs other than ethnic match between client and therapist that account for why Mexican American clients are less likely to drop out of treatment and attend more sessions when participating in these programs, A better understanding of the specific influences of ethnic-specific mental health programs (e.g., ethnic match, bilingual therapists, therapist sensitivity and flexibility) on psychotherapeutic outcome can inform clinicians about the appropriateness of certain types of service delivery that will likely be beneficial to clients of varying Latino origin.

\section{SUMMARY}

Ensuring that Latino families receive the mental health care they need is increasingly important as the population of Latinos in the United States rises rapidly. One of the challenges in addressing the mental health issues of Latinos is their vast cultural heterogeneity. Fortunately, the utilization of mental health services by Latinos has been a growing focus of research and clinical practice. 
A variety of risk factors, such as socioeconomic conditions and acculturative stress, may contribute to the occurrence of mental health problems in Latinos. Although research clearly documents the need for mental health services, Latinos are overrepresented in low service utilization groups and in premature termination of services. The gap between the need for and the receipt of mental health services has prompted exploration of factors that account for this discrepancy.

The barriers to mental health services for Latinos are numerous and diverse. In addition to socioeconomic factors, a variety of cultural variables may contribute to the underutilization of mental health services, such as perceptions of mental illness, fatalism, spirituality, familism, cultural commitment, and language proficiency. Psychotherapeutic challenges associated with client-therapist interaction and assessment and therapy techniques also serve as barriers. To improve the accessibility and effectiveness of mental health services for Latinos, efforts to reduce the existing socioeconomic, cultural, and psychotherapeutic barriers are needed.

Clinical considerations suggest a variety of directions for improving the delivery of mental health services to Latino families. Increasing the dissemination of information about services and addressing practical challenges associated with time, costs, and location may improve accessibility. Continued efforts are also needed to better educate mental health practitioners, as well as physicians and clergy, on the issues, challenges, and culturally sensitive approaches. Language barriers must be reduced and client-therapist verbal communication facilitated. The cultural sensitivity and appropriateness of assessment and treatment procedures, and client participation in these services, must be improved. Although the empirical and clinical literature examining these issues has grown slowly but steadily, there are many more issues to be explored and services to be developed and provided.

\section{NOTES}

1. The term Hispanic/Latino is used to refer to persons of Mexican, Puerto Rican, Cuban, or Central and South American or other Spanish culture or origin, regardless of race (U.S. Census Bureau, 1996).

2. The term White is used to refer to persons of European or European-American culture or origin.

\section{ACKNOWLEDGMENTS}

We are thankful to Sherill Pineda for her editorial assistance on an earlier draft of this article and to Thea Rothmann for her helpful suggestions and attention to detail in the final draft of this article. We are also grateful to Jennifer Kincaid and Chris Noffke for their assistance with this project.

\section{REFERENCES}

Acosta, F. X. (1979). Barriers between mental health services and Mexican-Americans: An examination of a paradox. American Journal of Community Psychology, 7, 503-520.

Acosta, F. X. (1980). Self-described reasons for premature termination of psychotherapy by Mexican-American, Black American, and Anglo-American patients. Psychological Reports, 47, 435-443.

Acosta, F. X. (1982). Group psychotherapy with Spanishspeaking patients. In R. M. Becerra, M. Karno, \& J. I. Escobar (Eds.), Mental health and Hispanic Americans (pp. 183-197). New York: Grune \& Stratton.

Acosta, F. X. (1984).Psychotherapy with Mexican Americans: Clinical and empirical gains. In J. L. Martinez, Jr., \& Richard H. Mendoza (Eds.), Chicano Psychology (pp. 163-189). Orlando, FL: Academic Press.

Acosta, F. X., \& Cristo, M. H. (1981). Development of a bilingual interpreter program: An alternative model for Spanish-speaking services. Professional Psychology, 12, 474-482.

Acosta, F. X., \& Sheehan, J. G. (1976). Preferences toward Mexican American and Anglo American psychotherapists. Journal of Counseling and Clinical Psychology, 44, 272-279.

Adler, N. E., Boyce, T., Chesney, M. A., Cohen, S., Folkman, S., Kahn, R. L., \& Syme, S. L. (1994).Socioeconomic status and health: The challenge of the gradient. American Psychologist, 49, 15-24.

Akutsu, P. D., Snowden, L. R., \&. Organista, K. C. (1996). Referral patterns to ethnic-specific and mainstream programs for ethnic minorities and Whites. Journal of Counseling Psychology, 43 , 56-64.

Alegria, M., Canino, G., Rios, R., Vera, M., Calderon, J., Rusch, D., et al. (2002). Inequalities in use of specialty mental health services among Latino, African Americans, and Non-Latino Whites. Psychiatric Services, 53, 1547-1555.

Altarriba, J., \& Bauer, L. M. (1998). Counseling the Hispanic client: Cuban Americans, Mexican Americans, and Puerto Ricans. Journal of Counseling and Development, 76, 389-396. 
Alvidrez, J. (1999). Ethnic variations in mental health attitudes and service use among low-income African American, Latina, and European American young women. Community Mental Health Journal, 35, 515-530.

Alvidrez, J., Azocar, F., \& Miranda, J. (1996). Demystifying the concept of ethnicity for psychotherapy researchers. Journal of Counseling and Clinical Psychology, 64 , 903-908.

Amaro, H., \& Russo, N. F. (1987). Hispanic women and mental health: An overview of contemporary issues in research and practice. Psychology of Women Quarter$l y$, 11, 393-407.

American Psychological Association. (1993). Guidelines for providers of psychological services to ethnic, linguistic, and culturally diverse populations. American Psychologist, 48, 45-48.

Angel, R. J., \& Angel, J. L. (1996). The extent of private and public health insurance coverage among adult Hispanics. The Gerontologist, 36 , 332-340.

Antunes, G., Gordon, C., Gaitz, C., \& Scott, J. (1974). Ethnicity, socioeconomic status, and the etiology of psychological distress. Sociology and Social Research, 58, 361-369.

Aponte, J. F., \& Barnes, J. M. (1995). Impact of acculturation and moderator variables on the intervention and treatment of ethnic groups. In J. F. Aponte, R. Y. Rivers, \& J. Wohl (Eds.), Psychological interventions and cultural diversity (pp. 19-39). Needham Heights, MA: Allyn \& Bacon.

Aponte, J. F., \& Crouch, R. T. (1995). The changing profile of the United States. In J. F. Aponte, R. Y. Rivers, \& J. Wohl (Eds.), Psychological interventions and cultural diversity (pp. 1- 18). Needham Heights, MA: Allyn \& Bacon.

Arredondo, P. (1991). Counseling Latinos. In C. C. Lee \& B. L. Richardson (Ed.), Multicultural issues in counseling (pp. 143-156). Alexandria, VA: American Association of Counseling and Development.

Arredondo, P. (1996). MCT theory and Latina(o)-American populations. In D. W. Sue, A. E. Ivey, \& P. B. Pedersen (Eds.), A theory of multicultural counseling and therapy (pp. 217-235). Pacific Grove, CA: Brooks/Cole.

Arredondo, P., Toporek, R., Brown, S. P., Jones, J., Locke, D. C., Sanchez, J., et al. (1996). Operationalization of the multicultural counseling competencies. Journal of Multicultural Counseling and Development, 24, 42-78.

Arroyo, J. A. (1996). Psychotherapist bias with Hispanics: An analog study. Hispanic Journal of Behavioral Sciences, 18, 21-28.

Atkinson, D. R., Casas, A., \& Abreu, J. (1992). MexicanAmerican acculturation, counselor ethnicity and cul- tural sensitivity, and perceived counselor competence. Journal of Counseling Psychology, 39, 515-520.

Atkinson, D. R., \& Lowe, S. M. (1995). The role of ethnicity, cultural knowledge, and conventional techniques in counseling and psychotherapy. In J. G. Ponterotto, J. M. Casas, L. A. Suzuki \& C. M. Alexander (Eds.), Handbook of multicultural counseling (pp. 387-414). Thousand Oaks, CA: Sage.

Atkinson, D. R., Ponce, F. Q., \& Martinez, F. M. (1984). Effects of ethnic, sex, and attitude similarity on counselor credibility. Journal of Counseling Psychology, 31, 588-590.

Belitz, J., \& Valdez, D. M. (1997). A sociocultural context for understanding gang involvement among Mexican-American male youth. In J. G. Garcia \& M. C. Zea (Eds.). Psychological interventions and research with Latino populations. (pp. 56-72). Needham Heights, MA: Allyn \& Bacon.

Berk, M. L., Albers, L. A,, \& Schur, C. L. (1996). The growth in the U.S. uninsured population: Trends in Hispanic subgroups, 1977 to 1992. American Journal of Public Health, 86, 572-76.

Bernal, G., Bonilla, J., Padilla-Cotto, L., \& Perez-Prado, E. M. (1998). Factors associated to outcome in psychotherapy: An effectiveness study in Puerto Rico. Journal of Clinical Psychology, 54, 329-342.

Bernal, G., \& Scharron-Del-Rio, M. R. (2001). Are empirically supported treatments valid for ethnic minorities? Toward an alternative approach for treatment research. Cultural Diversity and Ethnic Minority Psychology, 7, 328-342.

Berrigan, L. P., \& Garfield, S. L. (1981). Relationship of missed psychotherapy appointments to premature termination and social class. The British Journal of Clinical Psychology, 20, 239-242.

Berry, J. W. (1990). Psychology of acculturation. In R. W. Brislin (Ed.), Applied cross-cultural psychology (pp. 232-253). Newbury Park. CA: Sage.

Berry, J. W. (1993). Ethnic identity in plural societies. in M. E. Bernal \& G. P. Knight (Eds.), Ethnic identity: Formation and transmission among Hispanics and other minorities (pp. 271- 296). Albany, NY: State University of New York.

Berry, J. W., \& Kim, U. (1988). Acculturation and mental health. In P. Dasen, J. W. Berry, \& N. Sartorius (Eds.), Health and cross-cultural psychology: Towards application (pp. 207-236). London: Sage.

Bonicatto, S., Dew, A. M., \& Soria, J. J. (1998). Analysis of the psychometric properties of the Spanish version of the Beck Depression Inventory in Argentina. Psychiatry Research, 79, 277-285. 
Borrego. R. L., Chavez, E. L., \& Titley, R. W. (1982). Effects of counselor techniques on Mexican-American and Anglo-American self-disclosure and counselor perception. Journal of Counseling Psychology, 29, 538541.

Boulette, T. R. (1976). Determining needs and appropriate counseling approaches for Mexican-American women: A comparison of therapeutic listening and behavioral rehearsal. San Francisco: R and E Research Associates.

Brinson, J. A., \& Kottler, J. A. (1995). Minorities underutilization of counseling centers' mental health services: A case for outreach and consultation. Journal of Mental Health Counseling, 17, 371-385.

Brislin, R. W. (1994). Preparing to live and work elsewhere. In W. J. Lonner \& R. S. Malpass (Eds.), Psychology and Culture (pp. 239-244). Massachusetts: Allyn \& Bacon.

Bui, K. T., \& Takeuchi, D. T. (1992). Ethnic minority adolescents and the use of community mental health care services. American Journal of Community Psychology, 20, 403- 417.

Burnam, M. A, Hough, R . L., Karno, M., Escobar, J. I., \& Telles, C. A. (1987). Acculturation and lifetime prevalence of psychiatric disorders among Mexican Americans in Los Angeles. Journal of Health and Social Behavior, 28, 89-102.

Campbell, J. A. (1999). Health insurance coverage, 1998. In Current Population Reports. Washington, DC: U.S. Department of Commerce.

Canabal, M. E , \& Quiles, J. A. (1995). Acculturation and socioeconomic factors as determinants of depression among Puerto Ricans in the United States. Social Behavior and Personality, 23, 235-248.

Canino, G. (1982). The Hispanic woman: Sociocultural influences on diagnoses and treatment. In R. Becerra, M. Karno, \& J. Escobar (Eds.), Mental health and Hispanic Americans (pp. 117-138). New York: Grune \& Stratton.

Carlo, G., Carranza, M. A., \& Zamboanga, B. L. (2002). Culture, ecology, and Latinos on the Great Plains: An introduction. Great Plains Research, 12, 3-12.

Carter, K. T. (2003). Becoming racially and culturally competent: The racial-cultural counseling laboratory. Journal of Multicultural Counseling and Development, 31, 20-30.

Casas, M. J., \& Vazquez, M. J. T. (1989). Counseling the Hispanic client: A theoretical and applied perspective. In P. B. Pedersen, J. G. Draguns, W. J. Lonner, \& J. E. Trimble (Eds.), Counseling across cultures (pp. 15376). Honolulu: University of Hawaii Press.

Catanzarite, L. (2000). Brown-collar jobs: Occupational segregation and earnings of recent-immigrant Latinos. Sociological Perspectives, 43, 45-75.

Cervantes, R. C., Salgado de Snyder, V. N., \& Padilla, A. M. (1989). Post traumatic stress disorders among immigrants from Central America and Mexico. Hospital and Community Psychiatry, 40, 615-619.

Chandler, C. (1979). Traditionalism in a modern setting: A comparison of Anglo and Mexican-American value orientations. Human Organizations, 39, 153-159.

Cherbosque, J. (1987). Differences between Mexican and American clients' expectations about psychological counseling. Journal of Multicultural Counseling and Development, 15, 110-114.

Cheung, F. K. (1991). The use of mental health services by ethnic minorities. In H. F. Meyers, P. Wohlford, L. P. Guzman, \& K. J Echemendia (Eds.), Ethnic minority perspectives on clinical training and services in psychology (pp. 23-31). Washington, DC : American Psychological Association.

Cheung, F. K., \& Snowden, L. R. (1990). Community mental health and ethnic minority populations. Community Mental Health Journal, 26, 277-291.

Colon, E. (1996). Program design and planning strategies in the delivery of culturally competent health and mental health prevention and treatment services to Latino communities. Journal of Multicultural Social Work, 4, $85-96$.

Comas-Diaz, L., \& Griffith E. E. H., (Eds.). (1988). Clinical guidelines in cross-cultural mental health. New York: Wiley.

Cuellar, I., \& Roberts, R. E. (1997). Relations of depression, acculturation, and socioeconomic status in a Latino sample. Hispanic Journal of Behavioral Sciences, 19, 230-238.

Dana, R. H. (1995). Impact of the use of standard psychological assessment on the diagnosis and treatment of ethnic minorities. In J. F. Aponte, R. Y. Rivers, \& J. Wohl (Eds.), Psychological interventions and cultural diversity (pp. 57-73). Needham Heights, MA: Allyn \& Bacon.

Dohrenwend, D. P., Dohrenwend, B. S., Gould, M. S., Link, B., Neugebauer, R., \& Wunsch-Hitzig, R. (1980). Mental illness in the United States: Epidemiologic estimates. New York: Praeger.

Dressler, W., \& Bernal H. (1982). Acculturation and stress in a low-income Puerto Rican community. Journal of Human Stress, 8, 32-38.

Flaskerud, J. H. (1986). The effects of culture-compatible intervention on the utilization of mental health services by minority clients. Community Mental Health Journal, 22, 271-275. 
Flaskerud, J. H., \& Hu, L. (1992). Relationship of ethnicity to psychiatric disorders. The Journal of Nervous and Mental Disease, 180, 296-303.

Flisher, A. J., Kramer, R. A., Grosser, R. C., Alegria, M., Bird, H. R., Bourdon, K. H., et al. (1997). Correlates of unmet need for mental health services by children and adolescents. Psychological Medicine, 27, 1145-1154.

Frevert, V. S., \& Miranda, A. O . (1998). A conceptual formulation of the Latin culture and the treatment of Latinos from an Alderian psychology perspective. The Journal of Individual Psychology, 54, 291-309.

Gaitz, C., \& Scott, J. (1974). Mental health of MexicanAmericans: Do ethnic factors make a difference? Geriatrics, 29, 103-110.

Garfield, S. L. (1994). Research on client variables in psychotherapy. In A. E. Bergin \& S. L. Garfield (Eds.), Handbook of psychotherapy and behavior change (4th ed., pp. 190-228). New York: Wiley.

Garfield, S. L., \& Affleck, D. C. (1959). An appraisal of duration of stay in outpatient psychotherapy. Journal of Nervous \& Mental Disease, 129, 492-498.

Garland, A. F., Hough. R. L., Landsverk, J. A., McCabe, K. M., Yeh, M., Ganger, W. C., et al. (2000). Racial and ethnic variations in mental health care utilization among children in foster care. Children's Services: Social Policy, Research, and Practice, 3, 133-146.

Gaviria, M., \& Stern, G. (1980). Problems in designing and implementing culturally relevant mental health services for Latinos in the U.S. Social Science Medicine, 14B, 65-71.

Golding, J. M., \& Lipton, K. I. (1990). Depressed mood and major depressive disorder in two ethnic groups. Journal of Psychiatric Research, 24, 65-82.

Goldstein, A. P. (1981). Evaluating expectancy effects in cross-cultural counseling and psychotherapy. In A. J. Marsella \& P. B. Pedersen (Eds.), Cross-cultural counseling and psychotherapy (pp. 85-101). New York: Pergamon Press.

Gonzalez, G. M. (1997). The emergence of Chicanos in the twenty-first century: Implications for counseling, research, and policy. Journal of Multicultural Counseling \& Development, 25, 94-106.

Graham, J. R. (2000). MMPI-2: Assessing personality and psychopathology (3rd ed.). New York: Oxford University Press.

Greenblatt, M., \& Norman, M. (1982). Hispanic mental health and use of mental health services: A critical review of the literature. The American Journal of Social Psychiatry II, 3, 25-31.

Griffith, J. (1983). Relationship between acculturation and psychological impairments in adult Mexican Ameri- cans. Hispanic Journal of Behavioral Sciences, 5, 431459.

Guarnaccia, P. J., De La Cancella, V., \& Carrillo, E. (1989). The multiple meanings of ataques de nervios in the Latino community. Medical Anthropology, 11, 47-62.

Guarnaccia, P. J., Parra, P., Descamps, A,, Milstein, G., \& Argiles, N. (1991). Si Dios quiere: Hispanic families experiences of caring for a seriously mentally ill family member. Culture, Medicine, and Psychiatry, 16, 187215.

Guendelman, S., \& Wagner, T. H. (2000). Health services utilization among Latinos and White non-Latinos: Results from a national survey. Journal of Health Care for the Poor and Underserved, 11, 179-194.

Hovey, J. D., \& King, C. A. (1996). Acculturative stress, depression, and suicidal ideation among immigrant and second-generation Latino adolescents. Journal of the American Academy of Child and Adolescent Psychiatry, $35,1183-1192$.

Ibrahim, F. A. (1985). Effective cross-cultural counseling and psychotherapy. Psychotherapy, 22, 321-323.

Ibrahim, F. A., \& Arredondo, P. M. (1986). Ethical standards for cross-cultural counseling: Counselor preparation, practice, assessment, and research. Journal of Counseling and Development, 64, 349-352.

Jenkins, J. O., \& Ramsey, G. A. (1991). Minorities. In M. Hersen, A. Kazdin, \& A. Bellack (Eds.), The clinical psychology handbook (2nd ed., pp. 724-740). New York: Pergamon.

Jerrell, J. M. (1995). The effects of client-therapist match on service use and costs. Administration and Policy in Mental Health, 23(2), 119-126.

Kahn, M. W., \& Heiman, E. M. (1978). Factors associated with length of treatment in a barrio-neighborhood mental health service. International Journal of Social Psychiatry, 24, 259-262.

Karno, M., Hough, R. L., Burnam, M. A., Escobar, J. I., Timbers, D. M., Santana, F., et al. (1987). Lifetime prevalence of specific psychiatric disorders among Mexican-Americans and non-Hispanic whites in Los Angeles. Archives of General Psychiatry, 44, 695-701.

Keefe, S. E. (1979). Mexican Americans' underutilization of mental health clinics: An evaluation of suggested explanations. Hispanic Journal of Behavioral Sciences, 1, 92-113.

Keefe, S. E. (1982). Help-seeking behavior among foreignborn and native-born Mexican Americans. Social Science and Medicine, 16, 1467-1472.

Keefe, S. E., \& Casas, J. M. (1980). Mexican-Americans and mental health: A selected review and recommendations for mental health service delivery. American Jour- 
nal of Community Psychology, 8, 303-326.

Keefe, S. E., \& Padilla, A. M. (1987). Chicano ethnicity. Albuquerque, NM: University of New Mexico Press.

Keefe, S. E., Padilla, A. M., \& Carlos, M. L. (1979). The Mexican-American extended family as an emotional support system. Human Organizations, 38, 144-152.

Kopelowicz, A. (1997). Social skills training: The moderating influence of culture in the treatment of Latinos with schizophrenia. Journal of Psychopathology and Behavioral Assessment, 19, 101-108.

Kreisman, J. J. (1975). The curandero's apprentice: A therapeutic integration of folk and medical healing. American Journal of Psychiatry, 132, 81-83.

Kunkel, M. A. (1990). Expectations about counseling in relation to acculturation in Mexican-American and Anglo-American student samples. Journal of Counseling Psychology, 37, 286-292.

Lang, J. G., Munoz, R. E., Bernal. G., \& Sorensen, J. L. (1982). Quality of life and psychological well-being in a bi-cultural Latino community. Hispanic Journal of Behavioral Sciences, 4, 433-450.

Leong, F. T., Wagner, N. S., \& Tata, S. P. (1995). Racial and ethnic variations in help-seeking attitudes. In J. G. Ponterotto, J. M. Casas, L. A. Suzuki, \& C. H. Alexander (Eds.), Handbook of multicultural counseling (pp. 415-438). Thousand Oaks, CA: Sage.

Lopez, S. R. (2002). A research agenda to improve the accessibility and quality of mental health care for Latinos. Psychiatric Services, 53, 1569-1573.

Lorion, R. P., \& Felner, R. D. (1986). Research on mental health interventions with the disadvantaged. In S. L. Garfield \& A. E. Bergin (Eds.), Handbook of psychotherapy and behavior change (3rd ed., pp. 739-775). New York: Wiley.

Madsen, W. (1964). The Mexican-Americans of South Texas. New York: Holt, Rinehart, \& Winston.

Malgady, R. G., Rogler, L. H., \& Costantino, G. (1990). Culturally sensitive psychotherapy for Puerto Rican children and adolescents: A program of treatment outcome research. Journal of Counseling and Clinical Psychology, 58, 704-712.

Manoleas, P., Organista, K., Negron-Velasquez, G., \& McCormick, K. (2000). Characteristics of Latino mental health clinicians: A preliminary examination. Community Mental Health Journal, 36, 383-394.

Marcos, L. R., Urcuyo, L., Kesselman, M., \& Alpert, M. (1973). The language barrier in evaluating SpanishAmerican patients. Archives of General Psychiatry, 29, 655-659.

Marin, G. \& Marin, B. V. (1991). Research with Hispanic populations. Thousand Oaks, CA: Sage.
Martinez, C., (1993). Psychiatric care of Mexican Americans. In A. C. Graw (Ed.), Culture, ethnicity, and mental illness (pp. 431-466). Washington, DC: American Psychiatric Press.

Martinez, C. (1988). Mexican-Americans. In L. ComasDiaz \& E. Griffith (Eds.), Clinical guidelines in crosscultural mental health (pp. 182-203). New York: Wiley.

McRae. M. B., \& Johnson, S. D. (1991). Towards training for competence in multicultural counselor education. Journal of Counseling and Development, 70, 131-135.

Miranda, A. O., \& Umhoefer, D. L. (1998). Depression and social interest differences between Latinos in dissimilar acculturation stages. Journal of Mental Health Counseling, 20, 159-171.

Miranda, A. O., \& White, P. E. (1993). The relationship between acculturation level and social interest among Hispanic adults. Individual Psychology, 49, 76-85.

Miranda, M. R., Andujo, E., Guerrero, C. C., Caballero, I. L., \& Ramos, R. A. (1976). Mexican-American dropouts in psychotherapy as related to level of acculturation. In M. R. Miranda (Ed.), Psychotherapy with the Spanish-speaking: Issues in research and service delivery (Monograph No. 3). Los Angeles: UCLA Spanish Speaking Mental Health Research Center.

Moore, J. W. (1970). Mexican-American. Englewood Cliffs, NJ: Prentice-Hall.

Munoz, R. F., \& Ying, Y. W. (1993). The prevention of depression. Baltimore: John Hopkins University Press.

Nagayama Hall, G. C. (2001). Psychotherapy research with ethnic minorities: Empirical, ethical, and conceptual issues. Journal of Consulting and Clinical Psychology, 69, 502-510.

Neff, J. A. (1986). Alcohol consumption and psychological distress among U.S. Anglos, Hispanics, and Blacks. Alcohol and Alcoholism, 21, 111-119.

Neff, J. A., \& Hoppe, S. K. (1993). Race/ethnicity, acculturation, and psychological distress: Fatalism and religiosity as cultural resources. Journal of Community Psychology, 21, 3-20.

Norquist, G., \& Wells, K. (1991). Mental health needs of the uninsured. Archives of General Psychiatry, 48, 475478.

Obazaki, S., \& Sue, S. (1995). Methodological issues in assessment research with ethnic minorities. Psychological Assessment, 7, 367-375.

Organista, K. C., Munoz, K. F., \& Gonzalez, G. (1994). Cognitive-behavioral therapy for depression in low income and minority outpatients: Description of a program and exploratory analyses. Cognitive Therapy and Research, 18, 241-259.

O’Sullivan, M. J., \& Lasso, B. (1992). Community mental 
health services for Hispanics: A test of the culture compatibility hypothesis. Hispanic Journal of Behavioral Sciences, 14, 455-468.

Padgett, D. K., Patrick, C., Burns, B. J., 8: Schlesinger, H. J. (1994a). Ethnic differences in the use of inpatient mental health services by Blacks, Whites, and Hispanics in a national insured population. Health Services Research, 29, 135-153.

Padgett, D. K., Patrick, C., Burns, B. J., \& Schlesinger, H. J. (1994b). Women and outpatient mental health services: Use by Black, Hispanic, and White women in a national insured population. Journal of Mental Health Administration, 21, 347-360.

Padilla, A. M. (1980). The role of cultural awareness and ethnic loyalty in acculturation. In A. M. Padilla (Ed.), Acculturation theory: Models and some new findings (pp. 47-84). Boulder, CO: Westview.

Padilla, A. M., Carlos, M. L., \& Keefe, S. E. (1976). Mental health service utilization by Mexican Americans. In M. R . Miranda (Ed.), Psychotherapy with the Spanish speaking: Issues in research and service delivery (Monograph No. 3). Los Angeles: UCLA Spanish Speaking Mental Health Research Center.

Padilla, A. M., Ruiz, R. A., \& Alvarez, R . (1975). Community mental health services for the Spanish-speaking/surnamed population. American Psychologist, 30, 892-905.

Padilla, A. M., \& Salgado de Snyder, N. (1985). Counseling Hispanics: Strategies for effective intervention. In P. Pedersen (Ed.), Handbook of cross-cultural counseling and therapy (pp. 157-164). Westport, CT: Greenwood Press.

Parker, M. P. (2000, November). Culturally responsive health care: The example of the Hmong in America. Paper presented at the National Conference on Family Relations, Minneapolis, MN.

Paz, J. (2002). Culturally competent substance abuse treatment with Latinos. Journal of Human Behavior in the Social Environment, 5, 123-136.

Pedersen, P. (1988). A handbook for developing multicultural awareness. Alexandria, VA: American Association for Counseling and Development.

Pedersen, P. ( 1994). A culture-centered approach to counseling. In W. J . Lonner\& R. S. Malpass (Eds.), Psychology and Culture (pp. 291-295). Needham Heights, MA: Allyn \& Bacon.

Pitta, P., Marcos, L., \& Alpert, M. (1978). Language switching as a treatment strategy with bilingual patients. American Journal of Psychoanalysis, 38, 255-258.

Pomales, J., \& Williams, V. (1989). Effects of level of acculturation and counseling style on Hispanic students' perceptions of counselor. Journal of Counseling Psychology, 36, 79-83.

Ponce, F. Q. \& Atkinson, D. R. (1989). Mexican-American acculturation, counselor ethnicity, counselor style, and perceived counselor credibility. Journal of Counseling Psychology, 36, 203-208.

Ponterotto, J. G. (1997). Multicultural counseling training: A competency model and national survey. In D. B. Pope-Davis \& H. L. K. Coleman (Eds.), Multicultural counseling competence: Assessment, education and training, and supervision (pp. 111-130). Thousand Oaks, CA: Sage.

Porter, N. (1994). Empowering supervisees to empower others: A culturally responsive supervision model. Hispanic Journal of Behavioral Sciences, 16, 43-56.

Pumariega, A. J., Glover, S., Holzer, C. E., III \& Nguyen, H. (1998). Utilization of mental health services in a tri-ethnic sample of adolescents. Community Mental Health Journal, 34, 1998.

Radloff, L. (1977). The CES-D scale: A self-report depression scale for research in the general population. $A p$ plied Psychological Measures, 1, 385-401

Ramirez, M. (1983). Psychology of the Americas: Mestizo perspective on personality and mental health. New York: Academic Press.

Regier, D. A, \& Kaelber, C. T. (1995). The Epidemiological Catchment Area (ECA) Program: Studying the prevalence and incidence of psychopathology. In M. T. Tsuang, M. Tohen, \& G. E. P. Zahner (Eds.), Textbook in psychiatric epidemiology (pp. 135-155). New York: Wiley.

Roberts, R. E., \& Sobhall, M. (1992). Symptoms of depression in adolescence: A comparison of Anglo, African, and Hispanic Americans. Journal of Youth and Adolescence, 21, 639-651.

Rogers, R., Flores, J., Ustad, K., \& Sewell, K. W. (1995). Initial validation of the Personality Assessment Inventory-Spanish version with clients from Mexican American communities. Journal of Personality Assessment, $64,340-348$.

Rogler, L. H., Cortes, D. E., \& Malgady, R. G. (1991). Acculturation and mental health status among Hispanics: Convergence and new directions for research. American Psychologist, 46 , 585-597.

Rogler, L. H., Gurak, D. T., \& Cooney, R. S. (1987). The migration experience and mental health: Formulations relevant to Hispanics and other immigrants. In M. Gaviria \& , J. D. Arana.( Eds.), Health and behavior: Research agenda for Hispanics (pp. 72-84). Chicago: University of Illinois Press.

Rogler, L. H., Malgady, R. G., Costantino, G., \& Blumen- 
thal, R. (1987). What do culturally sensitive mental health services mean? The case of Hispanics. American Psychologist, 42, 565-570.

Rogler, L. H., Malgady, R. G., \& Rodriguez, O. (1989). Hispanics and mental health: A framework for research. Malabar, FL: Krieger.

Rosenstein, M. J., Milazzo-Sayre, L. J., MacAskill, R. L., \& Manderscheid, R. W. (1987). Use of inpatient services by special populations. In R. W. Manderscheid \& S. A. Barrett (Eds.), Mental health, United States, 1987 (DHHS ADM 87-1518). Washington, DC: U.S. Government Printing Office.

Rossello, J., \& Bernal. G. (1999). The efficacy of cognitive-behavioral and interpersonal treatments for depression in Puerto Rican adolescents. Journal of Consulting and Clinical Psychology, 67, 734-745.

Ruiz, R. A., Casas, J. M., \& Padilla, A. M. (1977). Culturally relevant behavioristic counseling. Los Angeles: UCLA Spanish-Speaking Mental Health Research Center.

Russell, D. (1988). Language and psychotherapy: The influence of nonstandard English in clinical practice. In L. Comas-Diaz \& E. Griffith (Eds.), Clinical guidelines in cross-cultural mental health (pp. 3348). New York: Wiley.

Sabogal, F., Marin, G., Otero-Sabogal, R., Marin, B. V., \& Perez-Stable, E. J. (1987). Hispanic familism and acculturation: What changes and what doesn't? Hispanic Journal of Behavioral Sciences, 9, 397-412.

Salgado de Snyder, V. N. (1987). Factors associated with acculturative stress and depressive symptomatology among married Mexican immigrant women. Psychology of Women Quarterly, 11, 475-488.

Sanchez, A. R., \& Atkinson, D. R. (1983). Mexican-American cultural commitment, preference for counselor ethnicity, and willingness to use counseling. Journal of Counseling Psychology, 30, 215-220.

Sanchez, A. R., \& King, M. (1986). Mexican Americans' use of counseling services: Cultural and institutional factors. Journal of College Student Personnel, 27(4). 344-349.

Sandoval, M. C., \& De La Roza, M. C. (1986). A cultural perspective for serving the Hispanic client. In H. P. Lefley \& P. B. Pedersen (Eds.), Cross-cultural training for mental health professionals (pp. 151-182). Springfield, IL: Charles C. Thomas.

Santiago, A. M., \& Wilder, M. G. (1991). Residential segregation and links to minority poverty: The case of Latinos in the United States. Social Problems, 38, 492-515.

Schofield, W. (1964). Psychotherapy: The purchase of friendship. Englewood Cliffs, NJ: Prentice-Hall.
Sears, D. O. (1986). College sophomores in the laboratory: Influences of a narrow data base on psychology's view of human nature. Journal of Personality and Social Psychology, 51, 515-530.

Simons, A. D., Levine, J. L., Lustman, P. J., \& Murphy, G. E. (1984). Patient attrition in a comparative outcome study of depression: A follow-up report. Journal of Affective Disorders, 6, 163-173.

Smart, J. F., \& Smart, D. W. (1991). Acceptance of disability and the Mexican American culture. Rehabilitation Counseling Bulletin, 34, 357-367.

Snowden, L. R., \& Hines, A. M. (1994). Reaching the underserved: Mental health service systems and special populations. In W. J. Lonner \& R. S. Malpass (Eds.), Psychology and Culture (pp. 297-301). Needham Heights, MA: Allyn \& Bacon.

Snowden, L. R., Hu, T. W., \& Jerrell, J. M. (1995). Emergency care avoidance. Ethnic matching and participation in minority-serving programs. Community Mental Health Journal, 31, 463-473.

Stefl, M. E., \& Prosperi, D. C. (1985). Barriers to mental health service utilization. Community Mental Health Journal, 21, 167-1 78.

Sterling, R. C., Gottheil, E., Weinstein, S. P., \& Serota, R. (1998). Therapist/patient race and ethnic matching: Treatment retention and nine-month follow-up. Addiction, 93, 1043-1050.

Sue, D. W. (2001). Multidimensional facets of cultural competence. Counseling Psychologist, 29, 790-821.

Sue, D. W., Arredondo, P., \& McDavis, R. J. (1992). Multicultural competencies/standards: A call to the profession. Journal of Counseling and Development, 70, 477486.

Sue, D. W., Bernier, J. B., Durran, M., Feinberg, L., Pedersen, P., Smith, E., et al (1982). Position paper: Crosscultural counseling competencies. The Counseling Psychologist, 10, 45-52.

Sue, D. W., Carter, R. T., Casas, J. M., Fouad, N. A., Ivey, A. E., Jensen, M., et al. (1998). Multicultural counseling competencies: Individual and organizational development. Thousand Oaks, CA: Sage.

Sue. D. W., \& Sue, D. (1990). Counseling the culturally different: Theory and practice (2nd ed.). New York: Wiley.

Sue, D. W., \& Sue, D. (1999). Counseling the cultural$l y$ different: Theory and practice (3rd ed.). New York: Wiley.

Sue, S. (1977). Community mental health services to minority groups: Some optimism, some pessimism. American Psychologist, 32, 616-24.

Sue, S. (1988). Psychotherapeutic services for ethnic mi- 
norities: Two decades of research findings. American Psychologist, 43, 301-308.

Sue, S., Fujino, D. C., Hu, L. T., Takeuchi, D. T., \& Zane, N. W. S. (1991). Community mental health services for ethnic minority groups: A test of the cultural responsiveness hypothesis. Journal of Consulting and Clinical Psychology, 59, 533-540.

Sue, S., \& Zane, N. (1987). The role of culture and cultural techniques in psychotherapy: A critique and reformulation. American Psychologist, 42, 3745.

Szapocznik, J., \& Kurtines, W. (1980a). Acculturation, biculturalism, and adjustment among Cuban Americans. In A. Padilla (Ed.), Acculturation: Theory, models, and some new findings (pp. 27-42). Boulder, CO: Westview.

Szapocznik, J., S., Kurtines, W. (1980b). Bicultural involvement and adjustment in Hispanic American youths. International Journal of Intercultural Relations, 4, 353365.

Szapocznik, J., Rio, A, Murray, E., Cohen, R., Scopetta, M., Rivas-Vazquez, A, et al. (1989). Structural family versus psychodynamic child therapy for problematic Hispanic boys. Journal of Counseling and Clinical Psychology, 57, 571-578.

Takeuchi, D. T., Sue, S., \& Yeh, M. (1995). Return rates and outcome from ethnicity-specific mental health programs in Los Angeles. American Journal of Public Health, 85, 638-643.

Thamer, M., Richard, C., Casebeer, A. W., \& Fox-Nay, N. (1997). Health insurance coverage among foreign-born U.S. residents: The impact of race, ethnicity, and length of residence. American Journal of Public Health, 87, 96102.

Torrey, E. F. (1972). The mind game: Witchdoctors and psychiatrists. New York: Emerson Hall.

Trevino, F. M., Moyer, M. E., Burciaga Valdez, R., \& Stroup- Benham, C. A. (1992). Health insurance coverage and utilization of health services by Mexican Americans, Puerto Ricans, and Cuban Americans. In A. Furino (Ed.), Health policy and the Hispanic (pp. 158-170). Boulder, CO: Westview.

U.S. Census Bureau (1993). Current population reports: Hispanic Americans today. Washington, DC: U.S. Government Printing Office.

U.S. Census Bureau (1996). Population projections of the United States by age, sex, race, and Hispanic origin: 1995 to 2050. Washington, DC: U.S. Government Printing Office.

U.S. Census Bureau (2001a). The Hispanic population: 2000. Washington, DC: U.S. Government Printing Office.

U.S. Census Bureau (2001b). The Hispanic population in the United States: March 2000. Current population re- ports, P20-535. Washington, DC: U.S. Government Printing Office.

Vega, W. A., Kolody, B., Aguilar-Gaxiola. S., Alderete, E., Catalano, R., \& Caraveo-Anduaga, J. (1998). Lifetime prevalence of DSM-III-R psychiatric disorders among urban and rural Mexican Americans in California. Archive of General Psychiatry, 55, 771-778.

Vega, W. A., Kolody, B., Aguilar-Gaxiola, S., \& Catalano, R. (1999). Gaps in service utilization by Mexican Americans with mental health problems. American Journal of Psychiatry, 156, 928-934.

Vega, W. A,, \& Lopez, S. R. (2001). Priority issues in Latino mental health services research. Mental Health Services Research, 3, 189-200.

Velasquez, R. J., \& Gonzales, M. (1997). Use of the MMPI2 with Chicanos: Strategies for counselors. Journal of Multicultural Counseling and Development, 25, 107120.

Vernon, S., \& Roberts, R. (1982). Prevalence of treated and untreated psychiatric disorders in three ethnic groups. Social Science Medicine, 16, 1575-1582.

Wampold, B. E., Casas, J. M., \& Atkinson, D. R. (1981). Ethnic bias in counseling: An information processing approach. Journal of Counseling Psychology, 28, 498503.

Wells, K., Klap, R., Koike, A., \& Sherbourne, C. (2001). Ethnic disparities in unmet need for alcoholism, drug abuse, and mental health care. American Journal of Psychiatry, 158, 2027-2032.

Wells, K. B., Hough, R. L., Golding, J. M., Burman, M. A, \& Karno, M. (1987). Which Mexican-Americans underutilize health services? American Journal of Psychiatry, 144, 918-922.

Wierzbicki, M., \& Pekarik, G. (1993). A meta-analysis of psychotherapy dropout. Professional Psychology: Research and Practice, 24, 190-195.

Williams, C. L., \& Berry, J. W. (1991). Primary prevention of acculturative stress among refugees: Application of psychological theory and practice. American Psychologist, 46, 632-641.

Williams, D. R., \& Collins, C. (1995). US socioeconomic and racial differences in health: Patterns and explanations. Annual Review of Sociology, 21, 349-387.

Woodward, A. M., Dwinell, A. D., \& Arons, B. S. (1992). Barriers to mental health care for Hispanic Americans: A literature review and discussion. Journal of Mental Health Administration, 19, 224-236.

Submitted November 2002; accepted February 2003. 